\title{
Vibrational and Electronic Spectroscopy of Acenaphthylene and Its Cation
}

\author{
John Banisaukas, Jan Szczepanski, John Eyler, and Martin Vala* \\ Department of Chemistry and Center for Chemical Physics, University of Florida, \\ Gainesville, Florida 32611-7200
}

\author{
So Hirata \\ William R. Wiley Environmental Molecular Sciences Laboratory, Pacific Northwest National Laboratory, \\ P.O. Box 999, Richland, Washington 99352
}

\author{
Martin Head-Gordon \\ Department of Chemistry, University of California, Chemical Sciences Division, Lawrence Berkeley National \\ Laboratory, Berkeley, California 94720

\begin{abstract}
Jos Oomens, Gerard Meijer, and Gert von Helden
FOM Institute for Plasma Physics “Rijnhuizen”, P.O. Box 1207, 3430 BE Nieuwegein, The Netherlands, and Department of Molecular and Laser Physics, University of Nijmegen, P.O. Box 9010, 6500GL Nijmegen, The Netherlands
\end{abstract}

Received: August 29, 2002; In Final Form: December 2, 2002

\begin{abstract}
Various spectroscopic and photochemical properties of the acenaphthylene radical cation have been determined. Acenaphthylene cations were generated by low energy electron impact, deposited in solid argon at $12 \mathrm{~K}$, and studied via Fourier transform infrared (FT-IR) and visible/UV absorption spectroscopy. In addition, the gasphase IR spectrum of cationic acenaphthylene was obtained via multiphoton dissociation spectroscopy of the species stored in a quadrupole ion trap, using the intense and widely tunable radiation of a free electron laser. These two sets of results have been compared to the calculated (B3LYP/6-31G(d) and BP86/6-31G(d)) vibrational spectra of neutral and cationic acenaphthylene to aid in spectral band assignments. Large differences between the calculated IR intensity distributions of neutral and cationic acenaphthylene are predicted. The observed spectra are consistent with the predictions. The conversion of acenaphthylene $\left(\mathrm{C}_{12} \mathrm{H}_{8}\right)$ into acenaphthene $\left(\mathrm{C}_{12} \mathrm{H}_{10}\right)$ was observed upon deposition of acenaphthylene in an argon matrix with excess hydrogen atoms. The inverse conversion of acenaphthene $\left(\mathrm{C}_{12} \mathrm{H}_{10}\right)$ to acenaphthylene $\left(\mathrm{C}_{12} \mathrm{H}_{8}\right)$ was found to occur when the former species was exposed to UV radiation in the matrix. Calculations of the electronic excited states of the acenaphthylene cation and its hydrogenated cationic and neutral forms have been performed using time-dependent density functional theory (TDDFT), with SVWN/6-31(d,p), BLYP/6-31G(d,p), and B3LYP/6-31G(d,p) functionals/basis sets. Ten low-lying excited states were found theoretically for the cationic species. Three of these match closely with observed optical band energies. Finally, the photofragmentation pathways of the acenaphthene cation, a dihydrogenated product of acenaphthylene cation, were determined using Fourier transform ion cyclotron resonance (FT-ICR) mass spectrometry. The possible contribution of the acenaphthylene cation to the "unidentified interstellar infrared (UIR)" bands is discussed briefly.
\end{abstract}

\section{Introduction}

Polycyclic aromatic hydrocarbons (PAHs), in neutral, ionized, fragmented, and/or hydrogenated forms, are widely considered to be the carriers of the unidentified infrared emission bands. ${ }^{1-4}$ These bands, at 3.3, 6.2, 7.8, 8.6, and $11.3 \mu \mathrm{m}$, have been observed in the vicinity of many carbon- and hydrogen-rich galactic and extragalactic sources, and are thought to be produced in the outflow of carbon stars. ${ }^{5-7}$ Close proximity of a UV/visible source to the position of UIR activity is a necessary condition in the PAH model. UIR emission is initiated by the absorption of UV and/or visible radiation by a PAH molecule,

* Author to whom correspondence should be addressed. E-mail: mvala@ chem.ufl.edu. after which the excess energy flows into highly excited vibrational modes of the ground electronic state. Deactivation occurs via IR emission from the various modes of the PAH. While the frequencies of these modes match globally with the observed UIR bands, an exact match with a unique set of PAHs has not yet been made. Indeed, the observed intensity distribution of the IR spectral bands due to neutral PAHs does not mimic well the distribution of the UIR bands. A better intensity match has been found with laboratory IR spectra of PAH cations. ${ }^{8-11}$ Recent reports on the dependence of UIR intensity vs distance from an interstellar radiation source support the proposal that neutral and ionic PAHs are the origin of the UIR bands. ${ }^{12-15}$ While laboratory studies provide important information on the frequencies and relative intensities of the PAH cations, they do 
not address the question of the vibrational energy on the infrared emission process itself. However, Saykally and co-workers have recently reported on the single-photon IR emission spectroscopy of supersonic free-jet expansion and laser desorption of a number of neutral PAHs, ${ }^{16-17}$ as well as the pyrene cation. ${ }^{18}$ Increasing internal energy was found to broaden and red shift the emission bands. For those PAHs studied, a match with the UIRs was not found. However, it was surmised that larger PAH ions were probably better candidates for the UIR carriers.

While the possibility that PAHs may fragment in the vicinity of stellar sources has been discussed for some time, ${ }^{19}$ only recently have experimental studies begun to appear. Boissel and co-workers were the first to show that PAH cations ${ }^{20}$ subjected to short exposures of visible radiation were susceptible to fragmentation. These workers proposed that the primary step in this photodestruction was sequential multiphoton absorption. ${ }^{21}$

A Fourier transform ion cyclotron resonance mass spectrometric study showed that the coronene and naphthopyrene cations, exposed briefly to visible and ultraviolet radiation, could be stripped completely of their hydrogens. ${ }^{27}$ Another, more thorough study ${ }^{28}$ on a number of different PAHs (and other organic compounds) demonstrated that there are four different classes of behavior possible under a particular photon flux, viz., photostable, loss of only hydrogens, loss of hydrogens and carbons, and photodestruction. Of the photostable species, all possessed at least one four- or five-membered ring. The ease with which many of the PAHs were stripped of hydrogens and/ or carbons raises the question of the viability of PAHs in proximity to radiation sources. It further raises the question whether the observed photostable species could be major contributors to the UIR bands. Study of the neutral and ionic forms of these species is therefore needed to evaluate this possibility.

In this report the UV/Visible/IR absorption and photodissociation spectra and properties of one of these "photostable" species, acenaphthylene (ACN), as well as its hydrogenated, neutral, and cationic forms, are presented. The cationic species is of particular interest because of its predicted formation and photostability after acetylene loss from anthracene and phenanthrene cations. ${ }^{29}$ However, the matrix-isolated IR spectrum of the ACN cation appeared to be particularly difficult to analyze because of the formation of hydrogenated species in the matrix. To better understand these effects, two additional experiments were carried out. First, an independent infrared spectrum was recorded using infrared multiphoton dissociation spectroscopy of the gas-phase ions stored in a quadrupole trap. Second, reaction pathways were mapped out with the use of FT-ICR mass spectrometry.

IR photodissociation spectra of gas-phase $\mathrm{PAH}$ cations were recently reported. ${ }^{22-26}$ Mass-selected PAH cations stored in an ion trap are irradiated with the output of a free electron laser. This causes the internal energy of the PAHs to rise above the dissociation threshold through multiphoton absorption. The photodissociation spectra are recorded by monitoring the photofragment yield as a function of applied infrared wavelength.

\section{Experimental Methods}

The experimental instrumentation used for the UV/Visible/ IR cation absorption work is similar to that used in our earlier PAH studies. ${ }^{30,31}$ Briefly, an effusive beam of ACN (99+\%, Aldrich), was mixed with Ar isolant gas, passed through a Teflon needle valve, and directed at a $\mathrm{CsI}$ (or $\mathrm{BaF}_{2}$ ) window held at $12 \mathrm{~K}$ by a closed cycle helium cryostat (APD Displex). Just prior to deposition, the mixed beams were crossed by an electron beam from a homemade electron gun. The electron beam current was monitored by a $+60 \mathrm{~V}$ O-ring electrode located close to the cryostat window. The current, typically 1 $\mu \mathrm{A}$ with no Ar flowing, increased to $30 \mu \mathrm{A}$ with Ar flowing. This current increase is the result of secondary electrons detached mostly from Ar. Of the many possible ionization processes of PAHs, the main channels are likely to be Penning ionization involving metastable Ar*, electron transfer from $\mathrm{PAH}$ to $\mathrm{Ar}^{+}$ions, and direct electron impact. ${ }^{30}$ In some experiments, the Ar matrix gas was mixed with $\mathrm{CCl}_{4}(0.1 \%)$, which acts as an ionization enhancer, as well as a source of counterions (i.e., $\mathrm{Cl}^{-}$). The latter are necessary to balance the ACN and $\mathrm{Ar}$ cationic charges in the matrix.

To maintain the highest possible ratio of cations to neutrals in the matrix, a lengthy deposition (typically $6 \mathrm{~h}$ ) was required with a low concentration ratio of neutral PAH to Ar. Infrared and UV-Visible absorption spectra were recorded on a MIDAC or NICOLET Magna 560 Fourier transform IR spectrometer $\left(0.7 \mathrm{~cm}^{-1}\right.$ resolution in the $750-4000 \mathrm{~cm}^{-1}$ range or $0.5 \mathrm{~cm}^{-1}$ resolution in the $500-4000 \mathrm{~cm}^{-1}$ range, respectively) and on an IBM 9420 spectrophotometer $(0.28 \mathrm{~nm}$ resolution in the 220-900 nm), in an experimental configuration that allowed scanning of spectra on the same matrix in the two energy regions. Spectra were recorded both before and after photolysis with a $100 \mathrm{~W} \mathrm{Hg}$ lamp (full spectral output). An attempt to use Lyman radiation from atomic hydrogen as an ionization source ${ }^{31}$ failed to generate enough ACN cations to obtain their IR absorption spectrum, as noted by others in an earlier study. ${ }^{32}$

In the IR photodissociation experiment, vapor-phase ACN molecules were ionized using an ArF excimer laser and stored in a Paul-type quadrupole ion trap. ${ }^{26}$ The ACN cations were then photodissociated via multiphoton absorption using two 60 $\mathrm{mJ}$ macropulses (at $5 \mathrm{~Hz}$ repetition rate) from the Free Electron Laser for Infrared eXperiments (FELIX). FELIX was tuned over the $600-1700 \mathrm{~cm}^{-1}$ region and the fwhm laser bandwidth was ca. $0.6 \%$ of the incident photon energy. An infrared photodissociation spectrum was collected by using a time-of-flight (TOF) mass spectrometer to monitor the fragment mass intensity as a function of FELIX wavelength. Although the resolution of the ion trap/TOF mass spectrometer was insufficient to distinguish between fragment ions produced by single or double $\mathrm{H}$ loss from the parent ion, their appearance was clearly observable as a shoulder to the parent ion peak. Note that no carbon loss was observed for this species.

Photofragmentation pathways for the acenaphthene and ACN cations were investigated in detail using a $2 \mathrm{~T}$ Fourier transform ion cyclotron resonance (FT-ICR) mass spectrometer, ${ }^{33}$ equipped with a modular data acquisition system (MIDAS). ${ }^{34}$ Output from the UV/Visible excitation source, a $300 \mathrm{~W}$ Xe arc lamp (ILC Technology, model LX300UV), was pulsed on and off by a TTL signal-activated mechanical shutter (Vincent Associates, Uniblitz VS35S2ZM1R1). During ionization, electrons bombarding the sample were accelerated to $14 \mathrm{eV}$, more than sufficient to ionize both acenaphthene (IP $=7.7 \mathrm{eV}$ ) and ACN $(\mathrm{IP}=8.1 \mathrm{eV})$. Because significant fragmentation occurred during ionization, the parent ion was isolated using a stored waveform inverse Fourier transform (SWIFT) to eject unwanted fragments and any ${ }^{13} \mathrm{C}$ isotope-containing ions. Specific photoreaction pathways were studied by isolating the ion (parent or fragment) and observing the product mass spectrum during and after photolysis. 
$\mathbf{a}$

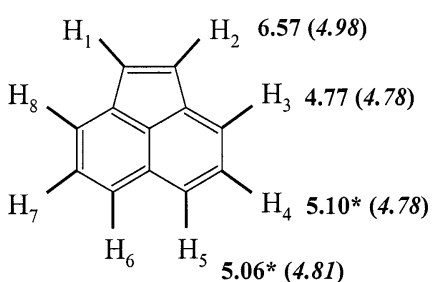

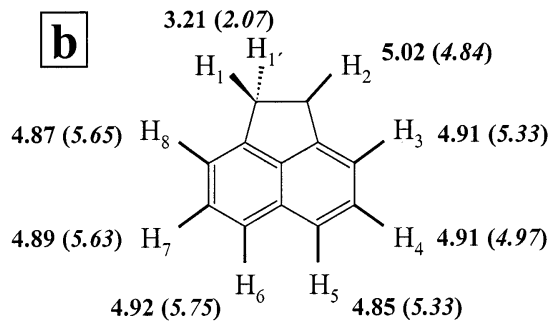

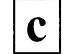

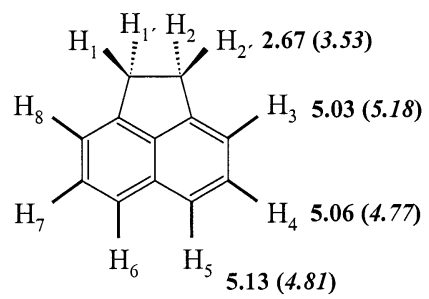

Figure 1. Structure of (a) acenaphthylene cation (neutral), $\mathrm{C}_{12} \mathrm{H}_{8}{ }^{+}$ $\left(\mathrm{C}_{12} \mathrm{H}_{8}\right)$; (b) singly hydrogenated acenaphthylene cation (neutral), $\mathrm{C}_{12} \mathrm{H}_{9}{ }^{+}\left(\mathrm{C}_{12} \mathrm{H}_{9}\right)$; and (c) doubly hydrogenated acenaphthylene (i.e., acenaphthene) cation (neutral), $\mathrm{C}_{12} \mathrm{H}_{10}{ }^{+}\left(\mathrm{C}_{12} \mathrm{H}_{10}\right)$. Values shown are the calculated $\mathrm{CH}$ bond energies $(\mathrm{eV})$ at $\mathrm{B} 3 \mathrm{LYP} / 6-31 \mathrm{G}(\mathrm{d}, \mathrm{p})$ for the cation (and neutral species, in italics and parentheses). The starred values indicate calculations with one imaginary frequency.

\section{Computational Methods}

Density functional theory calculations using the Gaussian 98 suite of programs ${ }^{35}$ with the B3LYP hybrid exchange-correlation functional ${ }^{36,37}$ and BP86 Becke's functional with nonlocal correlation provided by the Perdew 86 expression and 6-31G(d) or $6-31 \mathrm{G}(\mathrm{d}, \mathrm{p})$ basis sets were performed to predict the geometries and vibrational spectra for ACN and its hydrogenated forms, including acenaphthene. Geometry optimization at the B3LYP/6-31G (d) and BP86/6-31G (d) levels yielded $C_{2 v}$ geometry for both acenaphthylene and acenaphthene in neutral and cationic forms (cf., Figure 1).

In a comprehensive study of neutral and cationic PAHs containing six-membered rings, Langhoff 38 showed that the B3LYP/6-31G (d) and BP86/6-31G (d) levels of theory are sufficient for prediction of vibrational frequencies and relative intensities with good accuracy, even with basis sets smaller than 6-31G(d). Harmonic frequency calculations using the BP86/4$31 \mathrm{G}$ level of theory were performed by Bauschlicher et al. ${ }^{32}$ on a variety of PAHs containing five-membered rings. It was found that for some PAHs the BP86 method predicts frequencies with higher accuracy than the B3LYP method.

We estimated $\mathrm{CH}$ bond energies by subtracting the calculated energy of the precursor ion from the sum of the ground-state energies of the fragment ion and the hydrogen atom removed. All calculations employed the B3LYP method with the 6-31G(d,p) basis set. The zero-point energies (ZPE) were corrected by a factor of 0.978 before being incorporated into the total energy.
Breaking the lowest energy $\mathrm{CH}$ bond of the corresponding precursor ion identified the most probable fragment ion structures.

The vertical excitation energies and oscillator strengths of neutral ACN and its cation, acenaphthene cation, and dehydrogenated neutral acenaphthene and its cation were computed by the TDDFT method with Slater-Vosko-Wilk-Nusiar (SVWN), ${ }^{39,40}$ Becke-Lee-Yang-Parr (BLYP), ${ }^{37,41}$ and the hybrid Becke3-LeeYang-Parr (B3LYP) ${ }^{36}$ functionals using the Q-Chem 2.0 quantum chemistry program ${ }^{42}$ on IBM RS/6000 workstations. For the cationic species, whose low-lying excited states are primarily of the spatially compact valence type, we employed the $6-31 \mathrm{G}(\mathrm{d}, \mathrm{p})$ basis set. In a previous study we confirmed that this was an adequate basis set for vibrational frequency calculations of PAH cations. ${ }^{43}$ For neutral species, we employed the $6-31 \mathrm{G}(2+, 2+) \mathrm{G}(\mathrm{d}, \mathrm{p})$ basis set that contains two sets of diffuse basis functions to account for Rydberg or diffuse excited states that may be among the low-lying excited states. The optimized geometries were obtained from B3LYP/6-31G (d, p) calculations of the respective species. Using the Davidson trial vector algorithms, we sought the twenty lowest-lying excited states, but only the 10 lowest-lying excited states, of singlet spin multiplicity for closed-shell species, and approximate doublet spin multiplicity, for open-shell species, are presented here.

It has been shown that TDDFT, with the exchange-correlation functionals employed in this study, breaks down as the excitation energies exceed a certain threshold value, which was approximately the negative of the highest occupied KS orbital. ${ }^{44}$ The breakdown is due to the wrong (too rapid) asymptotic decay behavior of the exchange-correlation potentials. This causes an underestimation of the excitation energies of high-lying diffuse excited states. The threshold values computed with the BLYP functional are $5.20 \mathrm{eV}$ (ACN neutral), $10.1 \mathrm{eV}$ (ACN cation), $9.66 \mathrm{eV}$ (acenaphthene cation), $3.89 \mathrm{eV}$ (dehydrogenated acenaphthene neutral), and $9.99 \mathrm{eV}$ (dehydrogenated acenaphthene cation), respectively. The calculated vertical excitation energies of the cationic species are significantly smaller than these threshold values, and can safely be used to interpret the observed spectra. In general, TDDFT is capable of reproducing the vertical excitation energies of the low-lying excited states of PAH cations to within $0.3 \mathrm{eV}$ of the experimental result. ${ }^{31,43}$ It must be cautioned, however, that the threshold values for neutral species tend to be rather small, and the calculated excitation energies of the higher-lying excited states of the neutral species in the tables may be underestimated.

\section{Results and Discussion}

A. Infrared Absorption Spectra. 1. Neutral ACN. Part of the infrared absorption of neutral $\mathrm{ACN}$ isolated in solid $\mathrm{Ar}$ at $12 \mathrm{~K}$ is shown in Figure 2 (upper spectrum). Substructure can be seen on all bands, signifying that ACN may be isolated in a number of different matrix sites. Similar multisite structure has previously been observed for PAHs containing six-membered rings. ${ }^{10,11,30}$ The observed and calculated spectra are compared in Figure 2, and band frequencies and intensities are listed in Table 1. The experimental band intensities correspond to the sum of the multisite subband intensities. The overall correspondence between calculated and experimental band positions and relative intensities is quite good. All observed bands in the IR spectrum are assignable to bands predicted at the B3LYP/ 6-31G (d) and BP86/6-31G(d) levels of theory. A uniform scaling factor of 0.97 was applied to all harmonic B3LYP/6$31 \mathrm{G}(\mathrm{d})$ frequencies to account for mode anharmonicities, while 
TABLE 1: Comparison of the Calculated (B3LYP/6-31G(d) and BP86/6-31G(d)) and Experimental (Ar matrix, 12 K) Infrared Absorption Spectra of Neutral Acenaphthylene (frequencies in $\mathbf{c m}^{-1}$, relative intensities in parentheses)

\begin{tabular}{|c|c|c|c|c|}
\hline \multirow{2}{*}{$\begin{array}{c}\text { mode } \\
\text { symm. and descrip. }{ }^{a}\end{array}$} & \multicolumn{2}{|c|}{ calculated freq. $/ \mathrm{cm}^{-1}$} & \multicolumn{2}{|c|}{ experimental (Ar matrix) } \\
\hline & $\mathrm{B} 3 \mathrm{LYP}^{b, c}$ & ${\mathrm{BP} 86^{d}}^{2}$ & freq. $/ \mathrm{cm}^{-1 e}$ & rel. int. ${ }^{f}$ \\
\hline$b_{1} ; \tau(\mathrm{CCC})$ & $162.7(0.06)$ & $162.1(0.07)$ & & \\
\hline$b_{1} ; \tau(\mathrm{CCC})$ & $226.9(0.05)$ & $225.3(0.06)$ & & \\
\hline$a_{1} ; \alpha(\mathrm{CCC})$ & $410.7(0.03)$ & $410.8(0.03)$ & & \\
\hline$b_{2} ; \alpha(\mathrm{CCC})$ & $457.9(0.02)$ & $458.7(0.02)$ & & \\
\hline$b_{2} ; \alpha(\mathrm{CCC})$ & $503.4(0.03)$ & $502.0(0.03)$ & & \\
\hline$a_{1} ; \alpha(\mathrm{CCC})$ & $543.3(0.06)$ & $542.4(0.05)$ & $551.2,552.1$ & $(0.04)$ \\
\hline$b_{1} ; \epsilon(\mathrm{CH})+\tau(\mathrm{CCC})$ & $726.0(0.61)$ & $718.0(0.63)$ & $727.3,732.8$ & $(0.71)$ \\
\hline$b_{1} ; \epsilon(\mathrm{CH})+\tau(\mathrm{CCC})$ & $772.0(0.60)$ & $763.4(0.65)$ & $773.7,775.0$ & $(0.42)$ \\
\hline$b_{1} ; \epsilon(\mathrm{CH})+\tau(\mathrm{CCC})$ & $836.1(0.69)$ & $826.8(0.71)$ & $832.4,829.1$ & $(0.71)$ \\
\hline$b_{2} ; \epsilon(\mathrm{CH})+\tau(\mathrm{CCC})$ & $852.5(0.06)$ & $851.6(0.06)$ & $866.6,864.1$ & $(0.07)$ \\
\hline$b_{1} ; \epsilon(\mathrm{CH})+\tau(\mathrm{CCC})$ & $901.0(0.04)$ & $888.4(0.04)$ & $910.5,913.0$ & $(0.03)$ \\
\hline$b_{1} ; \epsilon(\mathrm{CH})+\tau(\mathrm{CCC})$ & $947.5(0.03)$ & $932.0(0.03)$ & $967.3,966.1$ & $(0.01)$ \\
\hline$a_{1} ; \beta(\mathrm{CH})+R(\mathrm{CC})$ & $1000.5(0.04)$ & $1003.9(0.03)$ & 1012.5 & $(0.01)$ \\
\hline$a_{1} ; \beta(\mathrm{CH})+R(\mathrm{CC})$ & $1033.7(0.04)$ & $1039.2(0.03)$ & $1034.7,1030.6$ & $(0.01)$ \\
\hline$a_{1} ; \beta(\mathrm{CH})+R(\mathrm{CC})$ & $1082.7(0.20)$ & $1080.7(0.22)$ & $1080.1,1084.6$ & $(0.15)$ \\
\hline$b_{2} ; \beta(\mathrm{CH})+R(\mathrm{CC})$ & $1153.0(0.07)$ & $1158.8(0.04)$ & $1149.4,1152.6$ & $(0.07)$ \\
\hline$a_{1} ; \beta(\mathrm{CH})+R(\mathrm{CC})$ & $1177.1(0.06)$ & $1179.5(0.07)$ & $1180.7,1175.8$ & $(0.05)$ \\
\hline$b_{2} ; \beta(\mathrm{CH})+R(\mathrm{CC})$ & $1198.9(0.03)$ & $1198.8(0.01)$ & $1202.8,1204.2$ & $(0.11)$ \\
\hline$b_{2} ; \beta(\mathrm{CH})+R(\mathrm{CC})$ & $1217.0(0.09)$ & $1223.4(0.10)$ & $1223.0,1226.2$ & $(0.08)$ \\
\hline$a_{1} ; \beta(\mathrm{CH})+R(\mathrm{CC})$ & $1244.2(0.01)$ & $1245.1(0.01)$ & 1250.8 & $(0.01)$ \\
\hline$b_{2} ; \beta(\mathrm{CH})+R(\mathrm{CC})$ & $1308.1(0.01)$ & $1313.3(0.02)$ & $1307.0,1308.6$ & $(0.006)$ \\
\hline$a_{1} ; R(\mathrm{CC})+\beta(\mathrm{CH})$ & $1356.6(0.02)$ & $1358.1(0.01)$ & 1357.7 & $(0.003)$ \\
\hline$b_{2} ; R(\mathrm{CC})+\beta(\mathrm{CH})$ & $1394.9(0.06)$ & $1404.6(0.03)$ & $1390.1,1388.3$ & $(0.08)$ \\
\hline$a_{1} ; R(\mathrm{CC})+\beta(\mathrm{CH})$ & $1429.5(0.61)$ & $1445.7(0.57)$ & $1428.6,1429.6$ & $(0.59)$ \\
\hline$b_{2} ; R(\mathrm{CC})+\beta(\mathrm{CH})$ & $1460.6(0.31)$ & $1462.3(0.32)$ & $1461.0,1457.5$ & $(0.16)$ \\
\hline$b_{2} ; R(\mathrm{CC})$ & $1486.1(0.20)$ & $1485.3(0.19)$ & $1483.0,1477.3$ & $(0.17)$ \\
\hline$a_{1} ; R(\mathrm{CC})$ & $1512.2(0.20)$ & $1502.6(0.18)$ & $1498.5,1493.9$ & $(0.19)$ \\
\hline$b_{2} ; R(\mathrm{CC})$ & $1626.4(0.05)$ & $1620.8(0.04)$ & & \\
\hline$a_{1} ; r(\mathrm{CH})$ & 3093.3(0.13) & $3104.7(0.16)$ & $3062.0,3050.7$ & \\
\hline$a_{l} ; r(\mathrm{CH})$ & $3094.1(0.52)$ & $3105.3(0.51)$ & & $>(0.76)$ \\
\hline$b_{2} ; r(\mathrm{CH})$ & $3107.6(1.00)$ & $3119.6(1.00)$ & 3071.4 & \\
\hline$a_{l} ; r(\mathrm{CH})$ & $3108.7(0.28)$ & $3120.8(0.30)$ & & \\
\hline$b_{2} ; r(\mathrm{CH})$ & $3127.6(0.04)$ & $3143.3(0.05)$ & 3108.2 & $(0.03)$ \\
\hline$a_{1} ; r(\mathrm{CH})$ & $3146.8(0.36)$ & $3163.3(0.38)$ & 3120.9 & $(0.10)$ \\
\hline
\end{tabular}

${ }^{a}$ Notation used: $R$ and $r$ are stretching modes, $\alpha$ and $\beta$ are in-plane bending modes, and $\epsilon$ and $\tau$ are out-of-plane vibrations. ${ }^{b}$ Scaled by a factor of 0.97 . The integral intensity of the $3107.6 \mathrm{~cm}^{-1}$ band is equal to $57.4 \mathrm{~km} / \mathrm{mol}$. ${ }^{c}$ Only bands with relative intensities equal to or greater than 0.01 are listed. ${ }^{d}$ Unscaled frequencies. The integral intensity of the $3119.6 \mathrm{~cm}^{-1}$ band is equal to $58.1 \mathrm{~km} / \mathrm{mol} .{ }^{e}$ For each experimental band, only the most intense subbands are listed. ${ }^{f}$ Relative intensities scaled to the $832.4 / 829.1 \mathrm{~cm}^{-1}$ band as 0.71 . The bands in the $\mathrm{C}-\mathrm{H}$ stretching region are strongly overlapped, therefore, the assignment there is tentative.

BP86/6-31G(d) frequencies were left unscaled. From Figure 2, it can be concluded that both levels of theory describe the energies and relative intensities of neutral ACN reasonably well. However, because different modes have different anharmonicities, the use of a single scaling factor leads to a less-than-optimal match for several types of vibrational modes. For example, the B3LYP/6-31G (d) CH out-of-plane bending modes (around 950 $\mathrm{cm}^{-1}$ ) are shifted more than the $\mathrm{C}-\mathrm{C}$ stretching modes around $1500 \mathrm{~cm}^{-1}$ (cf., Table 1). The opposite is true for the $\mathrm{CH}$ stretching modes in the $3050-3100 \mathrm{~cm}^{-1}$ region. Nevertheless, except for the $\mathrm{CH}$ stretching modes, the differences between the remaining calculated and experimental frequencies are less than $20 \mathrm{~cm}^{-1}$.

Bauschlicher et al. conducted B3LYP/4-31G and BP86/4$31 \mathrm{G}$ calculations on neutral and cationic $\mathrm{ACN} .{ }^{32}$ In general, a basis set upgrade in such calculations is expected to have little influence on the calculated PAH IR spectra. ${ }^{32}$ However, comparison of the experimental frequencies and absorption band intensity distributions (Figure 2) with the calculated B3YP/4$31 \mathrm{G}$ and BP86/4-31G spectra $^{32}$ and the B3LYP/6-31G(d) spectrum (Figure 2) indicates that the B3LYP method coupled with a 6-31G(d) basis set reproduces the experimental band intensities of neutral ACN more accurately.

The ACN symmetry mode assignments given in Table 1 are based on the symmetries predicted by the B3LYP/6-31G(d) and BP86/6-31G(d) calculations. These assignments agree with the

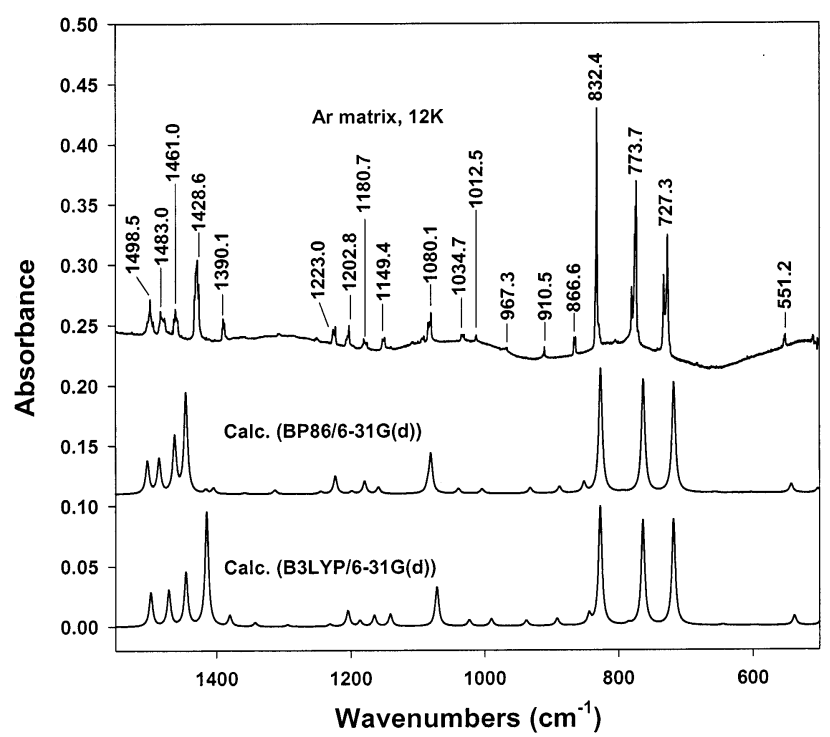

Figure 2. Comparison of the IR absorption spectrum of neutral acenaphthylene isolated in Ar matrix at $12 \mathrm{~K}$ (upper spectrum) with the calculated absorption spectrum at BP86/6-31G(d) and B3LYP/6$31 \mathrm{G}(\mathrm{d})$ levels (lower spectra). Theoretical harmonic frequencies are scaled by a factor of 0.97 for the B3LYP/6-31G (d) method and are unscaled for BP86/6-31G(d). The most intense experimental site bands are marked $\left(\right.$ in $\left.\mathrm{cm}^{-1}\right)$. 

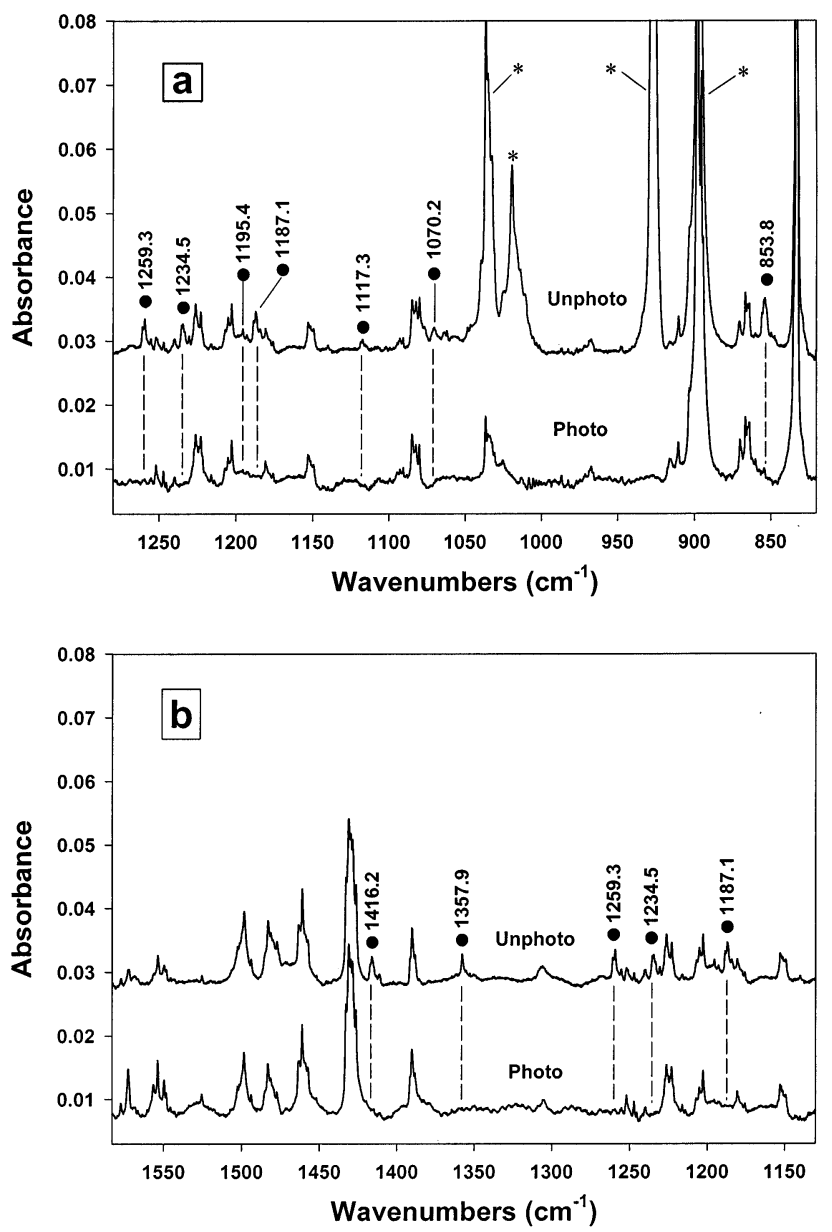

Figure 3. IR absorption spectrum of an Ar matrix containing neutral and cationic acenaphthylene with $0.1 \% \mathrm{CCl}_{4}$ (upper spectrum). Bottom spectrum produced by photolysis (for $2 \mathrm{~h}, 100 \mathrm{~W}$ medium-pressure $\mathrm{Hg}$ lamp, full output) of the upper spectrum matrix. IR absorption spectrum of acenaphthylene cation (bands marked with black dots, upper spectrum) shown for the (a) $825-1275 \mathrm{~cm}^{-1}$ and (b) $1125-1575 \mathrm{~cm}^{-1}$ regions.. Starred bands at 1036.6, 1018.9/927, and $898 \mathrm{~cm}^{-1}$ are due to the $\mathrm{CCl}_{3}{ }^{+}$cation, $\mathrm{CCl}_{3}{ }^{*} \mathrm{Cl}$ complex, and $\mathrm{CCl}_{3}$ fragment, respectively, and are electron-impact products of $\mathrm{CCl}_{4}$.

mode assignments reported by Radziszewski et al. ${ }^{45}$ from a linear dichroism IR absorption study of ACN aligned in stretched polyethylene films. However, in the $\mathrm{CH}$ stretching region, the symmetry assignments in Table 1 are tentative due to band overlap.

2. ACN Cation. As noted in earlier studies on PAHs containing six-membered rings ${ }^{8-11,30,31}$ and five-membered rings, ${ }^{32}$ dramatic differences in band intensity distributions are found theoretically for the neutral vs the cation for the same type of vibrational mode. Compared to the neutral species, the total integral intensity of the $\mathrm{CH}$ stretching modes of the acenaphthylene cation (in the $3050 \mathrm{~cm}^{-1}$ range) declines ca. 25 -fold, but increases only 2 -fold for the $\mathrm{C}-\mathrm{C}$ stretching mode region $\left(1610-1380 \mathrm{~cm}^{-1}\right)$. On the other hand, the cationic $\mathrm{CH}$ in-plane bending modes (in the $1300-1000 \mathrm{~cm}^{-1}$ region) increase by a factor of 14 , while the total intensity is practically unchanged for the $\mathrm{CH}$ out-of-plane modes (in the 900-700 $\mathrm{cm}^{-1}$ region).

Figure 3 shows part of the infrared absorption spectrum of the ACN cation trapped in solid Ar at $12 \mathrm{~K}$ (bands with dots in upper spectrum). This spectrum was recorded after electron beam ionization of an effusive beam containing $\mathrm{ACN} / \mathrm{Ar} / \mathrm{CCl}_{4}$ $(0.1 \%)$. Photolysis of the matrix liberated electrons from negatively charged species trapped in the matrix. ${ }^{31}$ These "free" electrons were trapped by ACN (and/or other) cations, resulting in an overall decline in cation concentration during UV photolysis. This effect can be seen in Figure 3 (lower spectrum) for the $1036.6 \mathrm{~cm}^{-1}$ band of the $\mathrm{CCl}_{3}{ }^{+}$cation, ${ }^{46}$ and for other bands assigned to the ACN cation. For all PAH cations studied by us to date (except for naphthalene), similar photolysis band behavior was observed.

In the matrix spectrum of the ACN cation, bands due to the hydrogenated species appear and they must be identified via correlation methods, which may sometimes be complicated. In the infrared photodissociation spectrum, the spectrum is due solely to the ACN cation, as this species is isolated in the ion trap prior to interrogation with FELIX. Moreover, the photodissociation spectrum yields valuable information on spectral regions which are obscured in the matrix (see Table 2) due to $\mathrm{CCl}_{4}, \mathrm{CCl}_{3}{ }^{(+)}$, or $\mathrm{H}_{2} \mathrm{O}$ bands. On the other hand, severe spectral congestion occurs in the photodissociation spectrum, particularly in the $1000-1400 \mathrm{~cm}^{-1}$ region, which is resolved in the matrix spectrum. Therefore, the matrix and photodissociation spectra are clearly complementary and the combination of the two experimental methods leads to a better understanding of the $\mathrm{ACN}$ cation infrared spectrum.

The photofragmentation mass spectrum of the ACN cation generated by multiphoton IR dissociation is shown in Figure 4. FELIX was tuned to the $815 \mathrm{~cm}^{-1}$ peak which is close to the strongest absorption band recorded for the ACN cation in an Ar matrix (cf., Figure 3a). Although the fragmentation yield is low, the $\mathrm{m} / \mathrm{z}, 150$ peak resulting from $\mathrm{H}_{2}$ loss from the parent ion is clearly visible. The photodissociation spectrum, obtained by plotting the intensity of the $\mathrm{m} / \mathrm{z}, 150$ mass peak vs the incident IR photon energy, is shown in Figure 5. In photodissociation spectra, IR bands are generally shifted to lower energies relative to matrix or gas-phase absorption bands. These shifts occur because highly excited vibrational states are involved in IR multiphoton dissociation processes, resulting in an energy spacing between adjacent states that is lowered by anharmonicity. The intensity distribution in the photodissociation spectrum does not always coincide with the absorption band intensity pattern, due to different anharmonicities for each mode, as was explicitly demonstrated for cationic coronene. Nonetheless, in general, IR photodissociation spectra show fair agreement with linear absorption data in terms of band positions as well as intensities.

Because the observed dissociation bands are very broad, deconvolution procedures were used to extract individual IR transitions. Because the number of bands assumed to be present in such a deconvoluted spectrum is arbitrary, the assignments of the bands at 924, 995, 1228, and $1398 \mathrm{~cm}^{-1}$ in Table 2 are somewhat tentative.

As is seen in Table 2, reasonable agreement is found between the line positions observed in the matrix and photodissociation spectra, if one takes into account the general red shift in the latter spectrum due to the influence of anharmonicity. In addition, the complementarity of the two spectra should be noted: the matrix spectrum resolves some of the bands that are heavily overlapped in the photodissociation spectrum (between 1000 and $1400 \mathrm{~cm}^{-1}$ ), whereas photodissociation spectral bands are observable in regions where the matrix spectrum is masked due to matrix contaminants. Only a few discrepancies are observed between the relative intensities of the two spectra.

Bauschlicher et al. have evaluated the accuracy of the B3LYP/ 4-31G and BP86/4-31G frequency calculations for some neutral and cationic PAHs containing five-membered rings. ${ }^{32}$ In a few 
TABLE 2: Calculated (B3LYP/6-31G(d) and BP86/6-31G(d)) and Experimental Vibrational Frequencies (in $\mathrm{cm}^{-1}$ ) of Infrared Absorption (Ar matrix, $12 \mathrm{~K}$ ) and Infrared Multiphoton Dissociation (using free electron laser, FEL) of the Acenaphthylene Cation (relative intensities in parentheses)

\begin{tabular}{|c|c|c|c|c|}
\hline \multirow{2}{*}{$\begin{array}{c}\text { mode } \\
\text { symm. and descrip. }{ }^{a}\end{array}$} & \multicolumn{2}{|c|}{ calculated freq. $/ \mathrm{cm}^{-1}$} & \multicolumn{2}{|c|}{ experimental freq./ $/ \mathrm{cm}^{-1}$} \\
\hline & $\mathrm{B} 3 \mathrm{LYP}^{b}$ & $\mathrm{BP}^{\circ} 6^{c}$ & Ar matrix & $\overline{\text { FEL dissoc. }}$ \\
\hline$b_{1} ; \tau(\mathrm{CCC})$ & $170.8(0.04)$ & $170.2(0.06)$ & & \\
\hline$b_{1} ; \tau(\mathrm{CCC})$ & $198.9(0.06)$ & $197.2(0.12)$ & & \\
\hline$b_{2} ; \alpha(\mathrm{CCC})$ & $425.6(0.32)$ & $444.4(0.31)$ & & \\
\hline$b_{1} ; \epsilon(\mathrm{CH})+\tau(\mathrm{CCC})$ & $749.5(0.27)$ & $746.3(0.50)$ & $d$ & $744(0.46)$ \\
\hline$b_{2} ; \epsilon(\mathrm{CH})+\tau(\mathrm{CCC})$ & $832.6(0.14)$ & $834.6(0.11)$ & & \\
\hline$b_{1} ; \epsilon(\mathrm{CH})+\tau(\mathrm{CCC})$ & $847.0(0.45)$ & $839.9(0.93)$ & $853.8(1.0)$ & $\begin{array}{l}817(0.59) \\
924(0.17)\end{array}$ \\
\hline$b_{2} ; \beta(\mathrm{CH})+R(\mathrm{CC})$ & 1015.7(0.39) & $1020.7(0.37)$ & $e$ & $995(0.40)$ \\
\hline$a_{1} ; \beta(\mathrm{CH})+R(\mathrm{CC})$ & $1062.3(0.18)$ & $1064.5(0.20)$ & $1076.7,1070.2(0.31)$ & $1063(0.63)$ \\
\hline$b_{2} ; \beta(\mathrm{CH})+R(\mathrm{CC})$ & & $1104.1(0.18)$ & $1117.3(0.23)$ & \\
\hline$b_{2} ; \beta(\mathrm{CH})+R(\mathrm{CC})$ & $1092.0(1.00)$ & $1134.2(0.88)$ & $1187.1(0.87)$ & $1183(1.00)$ \\
\hline$b_{2} ; \beta(\mathrm{CH})+R(\mathrm{CC})$ & $1185.7(0.31)$ & $1190.3(0.41)$ & $1195.4,1192.8(0.17)$ & \\
\hline$b_{2} ; \beta(\mathrm{CH})+R(\mathrm{CC})$ & $1224.7(0.22)$ & $1226.9(0.42)$ & $1235.4,1234.5(0.66)$ & \\
\hline$a_{1} ; \beta(\mathrm{CH})+R(\mathrm{CC})$ & $1257.5(0.39)$ & $1259.9(0.66)$ & $1259.3(0.75)$ & $1228(0.67)$ \\
\hline$a_{1} ; \beta(\mathrm{CH})+R(\mathrm{CC})$ & $1309.9(0.21)$ & $1312.2(0.16)$ & & \\
\hline$b_{2} ; R(\mathrm{CC})+\beta(\mathrm{CH})$ & $1345.8(0.09)$ & $1371.4(0.10)$ & $1357.9(0.21)$ & $1324(0.73)$ \\
\hline$a_{1} ; R(\mathrm{CC})+\beta(\mathrm{CH})$ & $1407.7(0.19)$ & $1423.5(0.22)$ & $1416.2(0.51)$ & $1398(0.50)$ \\
\hline$a_{1} ; R(\mathrm{CC})$ & $1448.8(0.05)$ & $1447.6(0.13)$ & & \\
\hline$b_{2} ; R(\mathrm{CC})$ & $1493.9(0.05)$ & $1491.7(0.06)$ & & \\
\hline$a_{1} ; R(\mathrm{CC})$ & $1550.7(0.06)$ & $1549.5(0.03)$ & & \\
\hline$a_{1} ; R(C C)$ & $1574.8(0.71)$ & $1576.1(1.00)$ & $f$ & $1566(0.73)$ \\
\hline$b_{2} ; R(\mathrm{CC})$ & $1608.4(0.07)$ & $1605.8(0.04)$ & & \\
\hline
\end{tabular}

${ }^{a}$ Notation used: $R$ and $r$ are stretching modes, $\alpha$ and $\beta$ are in-plane bending modes, and $\epsilon$ and $\tau$ are out-of-plane vibrations. In the modes of mixed character, the first mode indicated the largest contribution to total vibration. ${ }^{b}$ Scaled by a factor of 0.97 factor. The calculated integral intensity for the $1092.0 \mathrm{~cm}^{-1}$ band is $155 \mathrm{~km} / \mathrm{mol}$. ${ }^{c}$ Unscaled frequencies. The calculated integral intensity for the $1576.1 \mathrm{~cm}^{-1} \mathrm{band}$ is $84 \mathrm{~km} / \mathrm{mol}$. ${ }^{d}$ The $778-755 \mathrm{~cm}^{-1}$ and $797-781 \mathrm{~cm}^{-1}$ energy regions are not accessible, since they are masked by strong $\mathrm{CCl}_{4}$ bands. ${ }^{e}$ The $1040-1030 \mathrm{~cm}^{-1}$ and $1025-1010 \mathrm{~cm}^{-1}$ energy regions are covered by strong bands of $\mathrm{CCl}_{3}{ }^{+}$and $\mathrm{CCl}_{3} * \mathrm{Cl}$ complexes, respectively (cf., Figure $3 \mathrm{a}$ ). ${ }^{f}$ The $1598-$ $1588 \mathrm{~cm}^{-1}$ region is masked by the $\mathrm{H}_{2} \mathrm{O}$ band. ${ }^{g}$ Only relative intensities greater than 0.03 are listed.

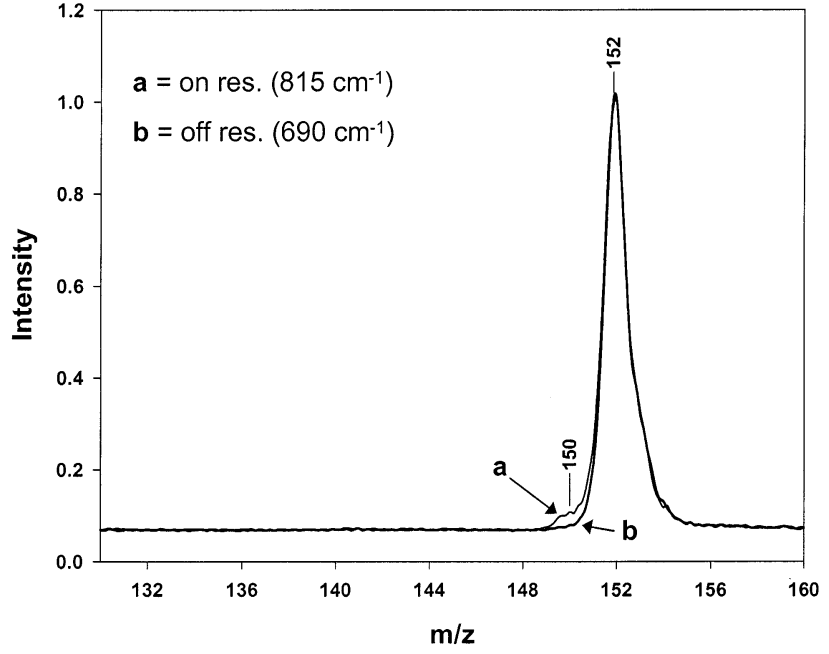

Figure 4. Time-of-flight mass spectra of acenaphthylene cation recorded with the IR free electron laser tuned on and off resonance. Only a small fraction of the ions exhibits fragmentation.

cases, the calculated intensity band pattern was very different using the B3LYP functional compared to the BP86 one. For neutral molecules, both functionals generated similar IR spectra, and showed good agreement with experiment.

To assess the accuracy of the frequency calculations for the ACN cation using these two functionals (with the 6-31G (d) basis set), and to make band assignments in the experimental Ar matrix spectrum (Figure 3), calculated frequencies and intensities are compared to experiment in Table 2 and Figure 6. The $853.8 \mathrm{~cm}^{-1}$ and $1187.1 \mathrm{~cm}^{-1}$ experimental bands are the most intense, and are here assigned to the out-of-plane $\mathrm{CH}$ and $\mathrm{C}-\mathrm{C}-\mathrm{C}$ vibrations and in-plane $\mathrm{CH}$ bending modes, respectively. The $1187.1 \mathrm{~cm}^{-1}$ mode contains a small contribution from the motion of internal $\mathrm{C}$ atoms not connected to any

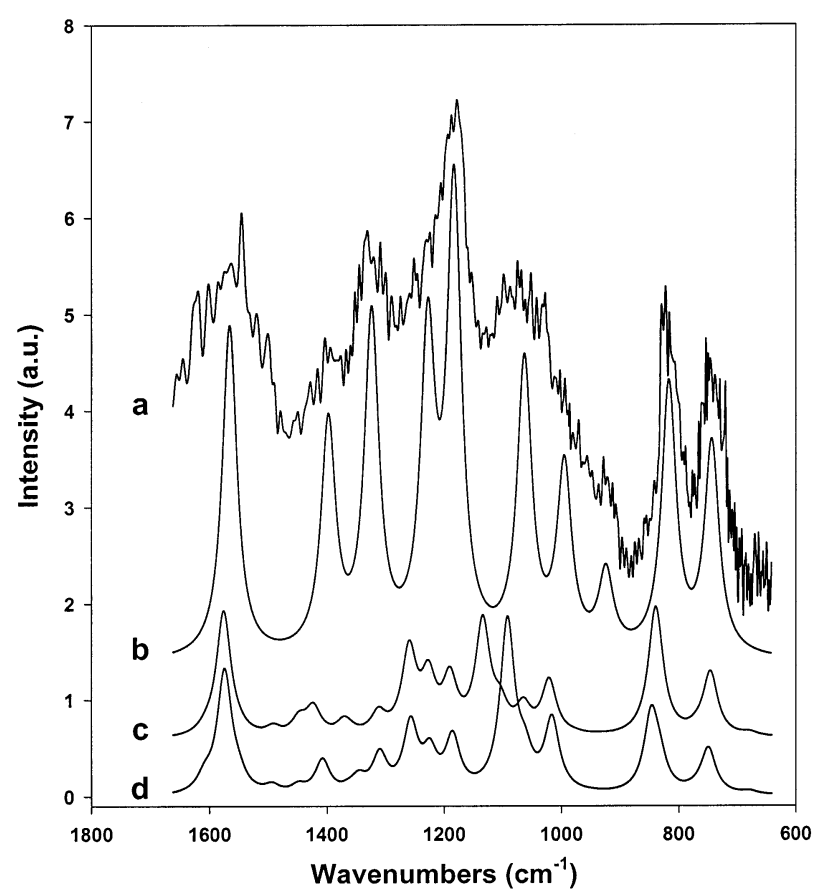

Figure 5. (a) Photodissociation spectrum of the acenaphthylene cation obtained using a tunable IR free electron laser (average of four spectra). (b) Deconvoluted spectrum of (a) with an assumed $30 \mathrm{~cm}^{-1}$ fwhm Lorentzian band profile. (c) BP86/6-31G(d) computed absorption spectrum, and (d) B3LYP/6-31G(d) computed absorption spectrum. Both spectra in (c) and (d) are convoluted with a $30 \mathrm{~cm}^{-1}$ fwhm Lorentzian band profile.

peripheral hydrogens. Comparing Figures 2 and 6, we conclude that both methods predict the fundamental mode frequencies in the ACN cation with an accuracy lower than for the neutral form. Also, from Figure 6, the calculated relative integral 


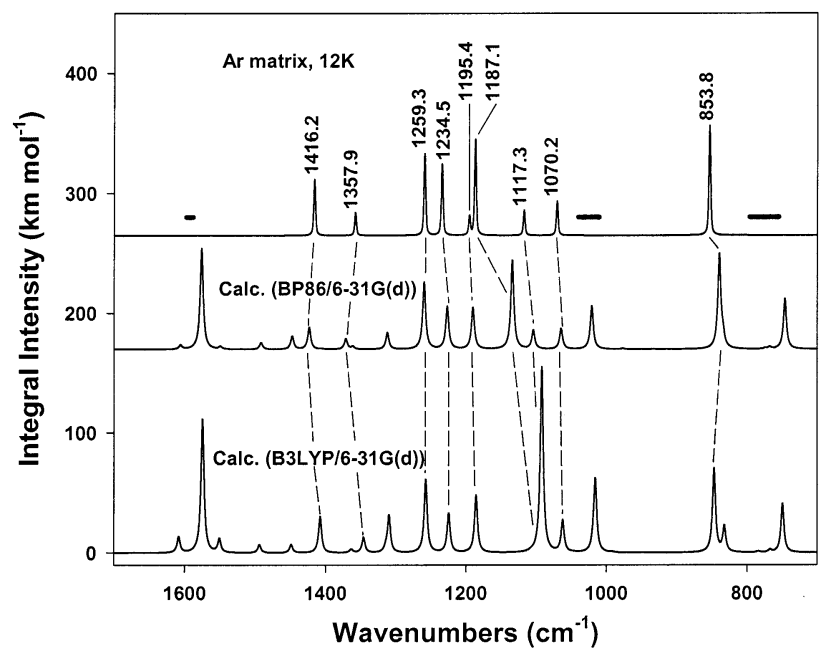

Figure 6. Comparison of computed vibrational absorption spectra of acenaphthylene cation with experimental data (upper trace). Harmonic frequencies from the B3LYP/6-31G(d) method were scaled by a factor of 0.97 , while frequencies from the BP86/6-31G(d) calculations were left unscaled. The experimental data are presented as a "synthetic" spectrum, created from experimental absorption bands extracted from Figure $3 a$ and $3 b$ (with the same energies and intensity ratios), and plotted on a relative intensity scale. Horizontal lines mark experimentally inaccessible energy regions (see text). Proposed band assignments are marked using dashed lines (see also Table 2).

intensities for the BP86 method are more accurate. Specifically, large relative intensity differences exist for the calculated $b_{1}$ and $b_{2}$ modes. Relative intensity differences of 0.45 vs 0.93 for the $853.8 \mathrm{~cm}^{-1}$ band and 0.22 vs 0.42 for the $1235.4 / 1234.5$ $\mathrm{cm}^{-1}$ band are found for B3LYP and BP86 calculations, respectively. Moreover, two $b_{2}$ modes with frequencies (intensities) of 1104.1(0.18) and $1134.2 \mathrm{~cm}^{-1}(0.88)$ are observed at the BP86 level, while for the B3LYP/6-31G(d) method two frequencies, 1092.0(1.00) and $1106.5 \mathrm{~cm}^{-1}$ (0.003) (or 1106.5 and $1092.0 \mathrm{~cm}^{-1}$ ), are calculated. However, due to mode mixing the intensity of $1106.5 \mathrm{~cm}^{-1}$ mode is transferred to the 1092 $\mathrm{cm}^{-1}$ mode, which becomes the most intense in the B3LYP/6$31 \mathrm{G}(\mathrm{d})$ spectrum (Table 2 and Figure 6). Expansion of the basis set beyond 6-31G $(\mathrm{d})$ has no significant effect on the calculated frequencies (after scaling), and little effect on the relative intensities. For example, in the BP86/6-31+G(d,p) spectrum of the ACN cation (not displayed), the frequencies are very close, after scaling, to those of BP86/6-31G(d), with the most intense band now assignable to the $853.8 \mathrm{~cm}^{-1}$ experimental vibration (cf., Table 2). Thus, relative experimental band intensities (in the Ar matrix spectrum) are described slightly better by the BP86/6-31+G(d,p) calculation; however, a relatively large energy shift to the red is observed for one $b_{1}$ mode with a frequency of $746.3 \mathrm{~cm}^{-1}$ [42km/mol](BP86/6-31G(d), unscaled) vs $701.0 \mathrm{~cm}^{-1}[27 \mathrm{~km} / \mathrm{mol}]$ (BP86/6-31+G(d,p), unscaled). This shift is not consistent with the observed FELIX dissociation band position at $744 \mathrm{~cm}^{-1}$ (cf., Table 2).

3. Singly and Doubly Hydrogenated Neutral ACN. Electron bombardment of $\mathrm{C}_{12} \mathrm{H}_{8}$ (plus a small amount of $\mathrm{H}_{2} \mathrm{O}$ ) may generate atomic hydrogen that can react with $\mathrm{C}_{12} \mathrm{H}_{8}$ on the relatively warm surface of the matrix. Because hydrogenation of the PAHs is exothermic, probably without any activation barrier, ${ }^{50,51}$ the following reactions are possible:

$$
\begin{gathered}
\mathrm{C}_{12} \mathrm{H}_{8}\left(\text { or } \mathrm{C}_{12} \mathrm{H}_{8}^{+}\right)+\mathrm{H}_{1^{\prime}} \rightarrow \mathrm{C}_{12} \mathrm{H}_{9}\left(\text { or } \mathrm{C}_{12} \mathrm{H}_{9}^{+}\right) \\
\mathrm{C}_{12} \mathrm{H}_{9}\left(\text { or } \mathrm{C}_{12} \mathrm{H}_{9}^{+}\right)+\mathrm{H}_{2^{\prime}} \rightarrow \mathrm{C}_{12} \mathrm{H}_{10}\left(\text { or } \mathrm{C}_{12} \mathrm{H}_{10}{ }^{+}\right. \text {) }
\end{gathered}
$$

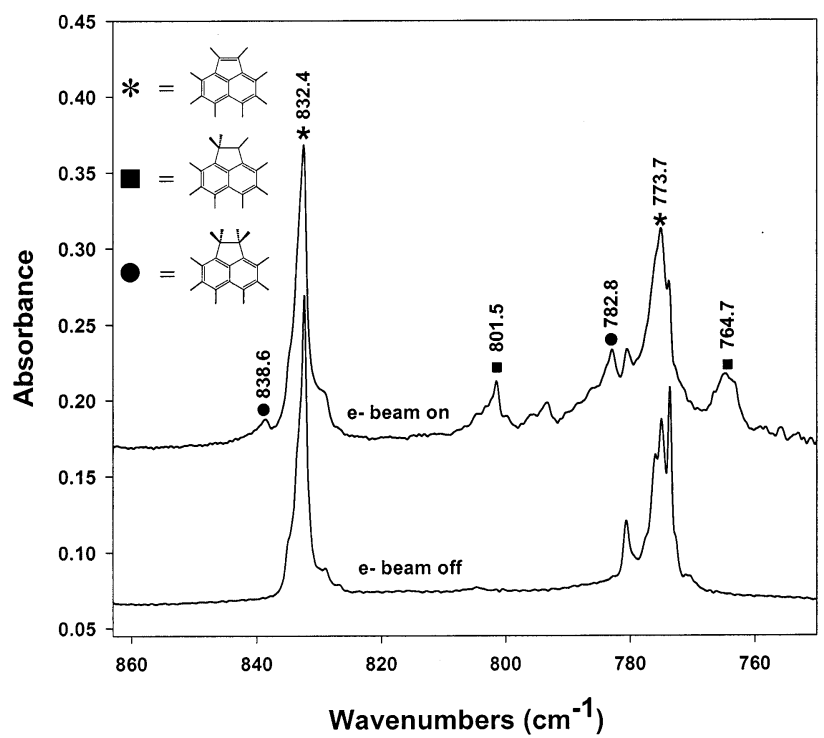

Figure 7. Part of the IR absorption spectrum showing the hydrogenation of acenaphthylene $\left(\mathrm{C}_{12} \mathrm{H}_{8}\right)$ isolated in solid $\mathrm{Ar}$ at $12 \mathrm{~K}$ (bottom spectrum) to form $\mathrm{C}_{12} \mathrm{H}_{9}$ radical (black squares) via the $\mathrm{C}_{12} \mathrm{H}_{8}+\mathrm{H}_{1^{\prime}}$ $\rightarrow \mathrm{C}_{12} \mathrm{H}_{9}$ reaction (see Figure 1 for $\mathrm{H}$ numbering) and doubly hydrogenated acenaphthylene $\left(\mathrm{C}_{12} \mathrm{H}_{10}\right.$, in the form of acenaphthene, black dots) probably in the $\mathrm{C}_{12} \mathrm{H}_{9}+\mathrm{H}_{2^{\prime}}$ (atomic $\mathrm{H}$ in position 2', see Figure 1) $\rightarrow \mathrm{C}_{12} \mathrm{H}_{10}$ reaction. Atomic hydrogen is generated during electron impact of hydrogen-bearing species, such as $\mathrm{C}_{12} \mathrm{H}_{8}$ and trace $\mathrm{H}_{2} \mathrm{O}$ impurities. The $780 \mathrm{~cm}^{-1}$ band (unmarked) is due to a trace of $\mathrm{CCl}_{4}$.

Figure 7 shows the IR absorption spectrum recorded after deposition of $\mathrm{ACN}$ in $\mathrm{Ar}$ at $12 \mathrm{~K}$, before electron beam bombardment (bottom) and after electron beam bombardment (top). The starred bands at 832.4 and $773.7 \mathrm{~cm}^{-1}$ are due to neutral ACN (cf., Figure 2). The most intense IR absorption bands calculated for singly hydrogenated neutral radical of ACN $\left(\mathrm{ACN}+\mathrm{H}_{1^{\prime}}\right)(\mathrm{cf}$. , Figure $1 \mathrm{~b})$ are $767 \mathrm{~cm}^{-1}$ [43 km/mol], 806 $\mathrm{cm}^{-1}$ [24 km/mol], $2946 \mathrm{~cm}^{-1}$ [29 km/mol], and $3128.2 \mathrm{~cm}^{-1}$ [43 km/mol], all scaled by a factor of 0.978 as typical for this calculational level. ${ }^{31}$ The experimental 801.5 and $764.7 \mathrm{~cm}^{-1}$ bands, marked with black squares, closely match the calculated bands of the singly hydrogenated $\mathrm{C}_{12} \mathrm{H}_{9}$ product at 806 and 767 $\mathrm{cm}^{-1}$.

Finally, the experimental 838.6 and $782.8 \mathrm{~cm}^{-1}$ bands, marked with black circles (cf., Figure 7, top), have absorption frequencies similar to the acenaphthene bands, measured independently in Ar. The most intense harmonic frequencies for neutral acenaphthene in this energy range are calculated (B3LYP/6-31G (d,p), scaled by 0.978 ) at 841.2 [15 km/mol] and $787.5 \mathrm{~cm}^{-1}[53 \mathrm{~km} / \mathrm{mol}]$. Thus, these experimental bands are ascribed here to neutral acenaphthene.

B. Electronic Absorption Spectra. 1. Neutral ACN. Table 3 shows the comparison between the calculated vertical excitation energies and the observed $0-0$ absorption bands in the visible/UV region for $\mathrm{ACN}$ isolated in $n$-pentane at $77 \mathrm{~K}^{48}$ and in solid Ar at $12 \mathrm{~K}$. The TDDFT method (with any of the three functionals) predicts the experimental absorption energies and oscillator strengths well.

2. ACN Cation. Vertical excitation energies calculated for the ACN cation are collected in Table 4, together with the results from two independent experiments. Three low-energy, lowintensity electronic transitions at $1550 \mathrm{~nm}(0.80 \mathrm{eV}), \sim 1080$ $\mathrm{nm}(1.15 \mathrm{eV})$, and $\sim 489 \mathrm{~nm}(2.53 \mathrm{eV})$ were observed by Shida in a butyl chloride matrix $(77 \mathrm{~K}) .^{50}$ These bands match closely the $0.77 \mathrm{eV}, 1.08 \mathrm{eV}$, and $2.65 \mathrm{eV}$ energy spacings between the vertical $\pi$ ionization potentials and the first ionization 
TABLE 3: Vertical Excitation Energies (eV) and Oscillator Strengths (in parentheses, "ia" represents inactive) of Neutral Acenaphthylene Calculated by Spin-Restricted TDDFT Employing the SVWN, BLYP, and B3LYP Functionals with the 6-31 $(2+, 2+) \mathbf{G}(\mathrm{d}, \mathrm{p})$ Basis Set ${ }^{a}$

\begin{tabular}{cllll}
\hline state $^{b}$ & SVWN & BLYP & B3LYP & experiment \\
\hline${ }^{1} \mathrm{~B}_{1}\left(\pi_{1} \leftarrow \pi_{-1}\right)$ & $2.82(0.0043)$ & $2.81(0.0047)$ & $3.08(0.0059)$ & $2.66(0.0042)^{c}$ \\
${ }^{1} \mathrm{~A}_{1}\left(\pi_{1} \leftarrow \pi_{-2}\right)$ & $3.60(0.0753)$ & $3.58(0.0765)$ & $3.85(0.1050)$ & $3.66(0.165)^{c}{ }^{c} 3.68^{d}$ \\
${ }^{1} \mathrm{~B}_{1}\left(\pi_{1} \leftarrow \pi_{-3}\right)$ & $3.93(0.0782)$ & $3.90(0.0780)$ & $4.16(0.0977)$ & $3.85,^{c} 4.02^{d}$ \\
${ }^{1} \mathrm{~A}_{1}\left(\pi_{2} \leftarrow \pi_{-1}\right)$ & $4.43(0.0190)$ & $4.41(0.0194)$ & $4.87(0.0246)$ & $4.51(0.005)^{c}$ \\
${ }^{1} \mathrm{~B}_{2}\left(\sigma_{1} \leftarrow \pi_{-1}\right)$ & $4.99(0.0000)$ & $4.66(0.0078)$ & $5.16(0.0120)$ & \\
${ }^{1} \mathrm{~A}_{2}\left(\sigma_{2} \leftarrow \pi_{-1}\right)$ & $5.22(\mathrm{ia})$ & $4.89(\mathrm{ia})$ & $5.39(\mathrm{ia})$ & $5.44(0.0002)$ \\
${ }^{1} \mathrm{~B}_{2}\left(\sigma_{3} \leftarrow \pi_{-1}\right)$ & $5.07(0.0084)$ & $4.96(0.0010)$ & $5.51(\mathrm{ia})$ & $5.39(0.867),{ }^{c} 5.45^{d}$ \\
${ }^{1} \mathrm{~A}_{2}\left(\sigma_{1} \leftarrow \pi_{-2}\right)$ & $5.34(\mathrm{ia})$ & $5.07(\mathrm{ia})$ & $5.58(0.4632)$ & \\
${ }^{1} \mathrm{~B}_{1}\left(\pi_{2} \leftarrow \pi_{-2}\right)$ & $5.13(0.1483)$ & $5.10(0.1441)$ & $5.74(0.0001)$ & \\
${ }^{1} \mathrm{~B}_{2}\left(\pi_{1} \leftarrow \sigma_{-1}\right)$ & $5.41(0.0013)$ & $5.16(0.0000)$ &
\end{tabular}

${ }^{a}$ The geometry is optimized at the B3LYP/6-31G $(\mathrm{d}, \mathrm{p})$ level. The carbon skeleton lies in the $x z$ plane with the longer molecular axis parallel to the $x$ axis. The ground-state wave function transforms as $\mathrm{A}_{1}$ irreducible representation in $C_{2 v}$ symmetry. ${ }^{b}$ The $\pi$ and $\sigma$ orbitals are numbered in the order of increasing orbital energies. The $\pi_{-1}$ and $\pi_{1}$ denote the highest occupied and the lowest unoccupied $\pi$ orbitals, respectively. ${ }^{c}$ In $n$-pentane at $77 \mathrm{~K}$, ref 48. ${ }^{d}$ In solid Ar, this work.

TABLE 4: Vertical Excitation Energies (eV) and Oscillator Strengths (in parentheses, "ia" represents inactive) of the Acenaphthylene Radical Cation Calculated by Spin-Unrestricted TDDFT Employing the SVWN, BLYP, and B3LYP Functionals with the 6-31G(d,p) Basis Set ${ }^{a}$

\begin{tabular}{cllll}
\hline state ${ }^{b}$ & \multicolumn{1}{c}{ SVWN } & BLYP & B3LYP & experiment \\
\hline${ }^{2} \mathrm{~A}_{2}\left(\pi_{0} \leftarrow \pi_{-1}\right)$ & $0.72(0.0037)$ & $0.75(0.0041)$ & $0.80(0.0054)$ & $0.80,{ }^{c} 0.17^{d}$ \\
${ }^{2} \mathrm{~B}_{2}\left(\pi_{0} \leftarrow \pi_{-2}\right)$ & $1.04(0.0010)$ & $1.08(0.0013)$ & $1.32(0.0022)$ & $1.15,{ }^{c} 0.77^{d}$ \\
${ }^{2} \mathrm{~A}_{2}\left(\pi_{1} \leftarrow \pi_{0}\right)$ & $2.52(0.0051)$ & $2.48(0.0060)$ & $2.60(0.0120)$ & $2.53,{ }^{c} 2.65^{d}$ \\
${ }^{2} \mathrm{~B}_{1}\left(\pi_{0} \leftarrow \sigma_{-1}\right)$ & $2.57(\mathrm{ia})$ & $2.85(\mathrm{ia})$ & $3.45(\mathrm{ia})$ & $3.18(0.0000)$ \\
${ }^{2} \mathrm{~B}_{2}\left(\pi_{0} \leftarrow \pi_{-}\right.$ & $2.92(0.0004)$ & $2.91(0.0004)$ & $3.66(0.0000)$ \\
${ }^{2} \mathrm{~A}_{1}\left(\pi_{0} \leftarrow \sigma_{-2}\right)$ & $2.75(0.0000)$ & $3.04(0.0000)$ & $3.59(0.0000)$ \\
${ }^{2} \mathrm{~A}_{2}\left(\pi_{0} \leftarrow \pi_{-4}\right)$ & $3.01(0.0017)$ & $3.04(0.0022)$ & $4.03(0.1514)$ \\
${ }^{2} \mathrm{~A}_{2}\left(\pi_{1} \leftarrow \pi_{-2}\right)$ & $3.83(0.1212)$ & $3.81(0.1164)$ & $4.52(\mathrm{ia})$ & \\
${ }^{2} \mathrm{~B}_{1}\left(\pi_{0} \leftarrow \sigma_{-3}\right)$ & $3.51(\mathrm{ia})$ & $3.81(\mathrm{ia})$ & $4.08(0.2625)$
\end{tabular}

${ }^{a}$ The geometry is optimized at the B3LYP/6-31G(d,p) level. The carbon skeleton lies in the $x z$ plane with the longer molecular axis parallel to the $x$ axis. The ground-state wave function transforms as $\mathrm{B}_{2}$ irreducible representation in $C_{2 v}$ symmetry. ${ }^{b}$ The $\pi$ and $\sigma$ orbitals are numbered in the order of increasing orbital energies. The $\pi_{-1}, \pi_{0}$, and $\pi_{1}$ denote the highest doubly occupied, the singly occupied, and the lowest unoccupied $\pi$ orbitals, respectively. ${ }^{c}$ Acenaphthylene cation trapped in butyl chloride matrix at $77 \mathrm{~K}$, reported by Shida, ref $50 .{ }^{d}$ Photoelectron spectrum of acenaphthylene, ref 49. Note that the large energy differences between the photoelectron bands of ACN neutral and the optical and calculated vertical excitation bands of ACN cation are due to the geometry changes in the cation vs the neutral species (see text).

potential $(8.22 \mathrm{eV})$ of neutral ACN. ${ }^{49}$ Furthermore, these transitions agree well with the TDDFT-calculated vertical excitation energies (cf., Table 4). The predicted values using three different functionals only differ from the experimental energies by $0.24 \mathrm{eV}$. It is of interest (see below) that all calculated electronic transitions up to ca. $2.6 \mathrm{eV}$ have very low oscillator strengths $(f)$, with the highest equal only to 0.012 .

Despite the apparent coincidence between the $0.80-\mathrm{eV}$ band in the electronic absorption spectrum and the $0.77-\mathrm{eV}$ peak (relative to the $8.22 \mathrm{eV}$ fundamental) in the photoelectron spectrum, ${ }^{49}$ we consider them to be different transitions. We assign the former to the transition to the lowest $\left({ }^{2} \mathrm{~A}_{2}\right)$ excited state while the latter is ascribed to the transition to the second lowest $\left({ }^{2} \mathrm{~B}_{2}\right)$ excited state. The transition energy to the lowest excited state is $0.17 \mathrm{eV}$, according to the photoelectron spectrum, which significantly differs from the calculated transition energy in Table $4(0.72-0.80 \mathrm{eV})$ or the observed electronic absorption peak position $(0.80 \mathrm{eV})$. These differences are due to the geometry changes in the cation where electronic absorption occurs (and on which the calculation of Table 4 is based) and in the neutral where the photoelectron transition takes place. At the neutral geometry (optimized using B3LYP/6-31G(d,p)), the TDDFT calculation(BLYP/6-31G(d,p)) predicts electronic transitions at $0.33\left({ }^{2} \mathrm{~A}_{2}\right), 0.63\left({ }^{2} \mathrm{~B}_{2}\right), 2.46\left({ }^{2} \mathrm{~B}_{1}\right)$, and $2.55\left({ }^{2} \mathrm{~A}_{2}\right)$ $\mathrm{eV}$, which agree reasonably well with the observed peak positions of the photoelectron spectrum at $0.17,0.77,2.5$, and $2.65 \mathrm{eV}$, respectively. Remarkably, the third lowest calculated transition is of $\pi^{*} \leftarrow \sigma$ type and is consistent with the observed $\sigma$ ionization threshold of $2.5 \mathrm{eV}$.

The visible absorption spectrum shown in Figure 8 (top) was recorded on the same Ar matrix as the IR spectra shown in Figure 3a, i.e., an electron-bombarded mixture of $\mathrm{ACN}$, Ar, and $0.1 \% \mathrm{CCl}_{4}$. The concentration of $\mathrm{ACN}$ cations in this matrix is very low, as evidenced by the weak IR absorption bands in Figure 3. Combined with the predicted low oscillator strengths of the low-energy electronic transitions, this makes it doubtful that any electronic transition of the ACN cation can be observed in this region. The question then arises: what is the origin of the observed bands in Figure 8? The upper spectrum, which originates from electron-bombarded ACN, is very similar to the lower spectrum which originates from electron-bombarded acenaphthene. It has already been shown (cf., Figure 7) that ACN can become hydrogenated in the matrix to form acenaphthene. Subsequent production of the acenaphthene cation by electron impact could then occur. Given the similarity of these two spectra and the known interconversion of ACN into acenaphthene in the matrix, we conclude that the upper spectrum in Figure 8 is due to acenaphthene cations, formed either by double-hydrogenation of ACN cations or by ionization of doubly hydrogenated neutral ACN (see below).

3. Acenaphthene Cation. Calculated vertical excitation energies support the above conclusion. As shown in Table 5, these energies, calculated using TDDFT methods, predict that the strongest transitions occur at energies which match the experimental absorption spectrum very well. The $655.7 \mathrm{~nm}(1.89 \mathrm{eV})$ 
TABLE 5: Vertical Excitation Energies (in $\mathrm{eV}$ ) and Oscillator Strengths (in parentheses, "ia" represents inactive) of the Acenaphthene Radical Cation Calculated by Spin-Unrestricted TDDFT Employing the SVWN, BLYP, and B3LYP Functionals with the 6-31G(d,p) Basis Set ${ }^{a}$

\begin{tabular}{|c|c|c|c|c|}
\hline state $^{b}$ & SVWN & BLYP & B3LYP & Experiment \\
\hline${ }^{2} \mathrm{~B}_{2}\left(\pi_{0} \leftarrow \pi_{-1}\right)$ & $1.27(0.0000)$ & $1.27(0.0000)$ & $1.36(0.0000)$ & $0.98^{d}$ \\
\hline${ }^{2} \mathrm{~B}_{2}\left(\pi_{0} \leftarrow \pi_{-2}\right)$ & $2.20(0.0397)$ & $2.15(0.0401)$ & $2.16(0.0509)$ & $1.88,{ }^{c} 1.94,{ }^{d} 1.89^{e}$ \\
\hline${ }^{2} \mathrm{~A}_{2}\left(\pi_{0} \leftarrow \pi_{-3}\right)$ & $2.75(0.0164)$ & $2.74(0.0110)$ & $2.98(0.0063)$ & $2.74,{ }^{c} 2.68,{ }^{d} 2.88^{e}$ \\
\hline${ }^{2} \mathrm{~B}_{1}\left(\pi_{0} \leftarrow \sigma_{-1}\right)$ & $2.87(0.0000)$ & $3.10(0.0000)$ & $3.59(0.0000)$ & \\
\hline${ }^{2} \mathrm{~A}_{1}\left(\pi_{0} \leftarrow \sigma_{-2}\right)$ & 2.96 (ia) & 3.16 (ia) & 3.67 (ia) & \\
\hline${ }^{2} \mathrm{~A}_{2}\left(\pi_{1} \leftarrow \pi_{0}\right)$ & $3.43(0.1047)$ & $3.38(0.1035)$ & $3.50(0.1151)$ & $3.20,{ }^{c} 3.23^{e}$ \\
\hline${ }^{2} \mathrm{~A}_{1}\left(\pi_{0} \leftarrow \sigma_{-3}\right)$ & 3.46 (ia) & 3.59 (ia) & 4.23 (ia) & \\
\hline${ }^{2} \mathrm{~B}_{1}\left(\pi_{0} \leftarrow \sigma_{-4}\right)$ & $3.49(0.0005)$ & $3.67(0.0005)$ & $4.26(0.0006)$ & \\
\hline${ }^{2} \mathrm{~A}_{2}\left(\pi_{0} \leftarrow \pi_{-4}\right)$ & $4.01(0.0078)$ & $4.11(0.0131)$ & $4.62(0.0405)$ & \\
\hline${ }^{2} \mathrm{~B}_{2}\left(\pi_{2} \leftarrow \pi_{0}\right)$ & $4.12(0.0025)$ & $4.13(0.0022)$ & $4.48(0.0037)$ & \\
\hline
\end{tabular}

${ }^{a}$ The geometry is optimized at the B3LYP/6-31G(d,p) level. The carbon skeleton lies in the $x z$ plane with the longer molecular axis parallel to the $x$ axis. The ground-state wave function transforms as $\mathrm{A}_{2}$ irreducible representation in $C_{2 v}$ symmetry. ${ }^{b}$ The $\pi$ and $\sigma$ orbitals are numbered in the order of increasing orbital energies. The $\pi_{-1}, \pi_{0}$, and $\pi_{1}$ denote the highest doubly occupied, the singly occupied, and the lowest unoccupied $\pi$ orbitals, respectively. ${ }^{c}$ Acenaphthene cation trapped in Freon matrix at $77 \mathrm{~K}$, reported by Shida. ${ }^{50}{ }^{d}$ Photoelectron spectrum of acenaphthene, ref 49. ${ }^{e}$ Acenaphthene cation isolated in solid $\mathrm{Ar}$ at $12 \mathrm{~K}$, this work.

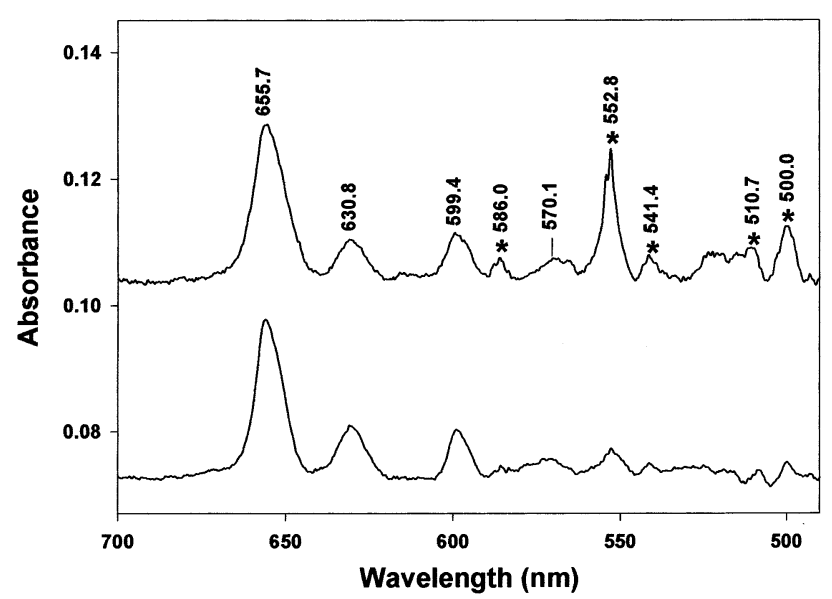

Figure 8. (a) Electronic absorption spectrum obtained for a matrix initially consisting of acenaphthylene, $\mathrm{Ar}$, and $0.1 \% \mathrm{CCl}_{4}$, after exposure to a $200 \mathrm{eV}$ electron beam (top spectrum) and (b) electronic absorption of the acenaphthene cation $\left(\mathrm{C}_{12} \mathrm{H}_{10}{ }^{+}\right)$in solid $\mathrm{Ar}$ generated by impact of $300 \mathrm{eV}$ electron beam with a mixture of acenaphthene, Ar and $0.1 \% \mathrm{CCl}_{4}$ (bottom spectrum). Both spectra are assigned to the ${ }^{2} \mathrm{~B}_{2}\left(\mathrm{D}_{2}\right)$ $\leftarrow{ }^{2} \mathrm{~A}_{2}\left(\mathrm{D}_{0}\right)$ electronic transition of the acenaphthene cation. The starred bands at 586.0 (2.12), 522.8 (2.24), 541.4 (2.29), 510.7 (2.43) and 500.0 $\mathrm{nm}(2.48 \mathrm{eV})$ are due to various (unknown) cationic and neutral fragments, which increase in concentration as the electron beam is applied.

experimental band (cf., Figure 8) is thus assigned to the ${ }^{2} \mathrm{~B}_{2}$ $\left(D_{2}\right) \leftarrow{ }^{2} A_{2}\left(D_{0}\right)(0-0)$ transition of the acenaphthene cation. The TDDFT energy for this transition falls at $2.16 \mathrm{eV}(f=$ 0.0509). The $0.27 \mathrm{eV}$ difference between calculated and observed transition energies is typical. From previous calculations of PAH excitation energies, differences of up to $0.3 \mathrm{eV}$ have often been found and are considered acceptable. ${ }^{31,43}$ The vibrational progression bands at 630.9 and $599.4 \mathrm{~nm}$ (Figure 8) are spaced 601 and $1432 \mathrm{~cm}^{-1}$, respectively, from the electronic absorption band at $655.7 \mathrm{~nm}$. The most intense symmetrical $\left(\mathrm{a}_{1}\right)$ harmonic Raman bands of the ground state of the acenaphthene cation are calculated (B3LYP/6-31G $(\mathrm{d}, \mathrm{p})$ ) at 630 [54] and $1437 \mathrm{~cm}^{-1}\left[109 \AA^{4} / \mathrm{amu}^{-1}\right]$, both scaled by 0.978 . The lowering of the symmetrical mode frequencies in the excited state compared to the ground state has been observed previously for the fluorene radical. ${ }^{53}$

The low intensity absorption band observed at $469 \mathrm{~nm}$ $(2.74 \mathrm{eV}),{ }^{49}$ and predicted at $2.98 \mathrm{eV}$ (TDDFT/B3LYP), is ascribed to the ${ }^{2} \mathrm{~A}_{2}\left(\mathrm{D}_{3}\right) \leftarrow{ }^{2} \mathrm{~A}_{2}\left(\mathrm{D}_{0}\right)$ transition. Finally, the strongest transition $\left[{ }^{2} \mathrm{~A}_{2}\left(\mathrm{D}_{6}\right) \leftarrow{ }^{2} \mathrm{~A}_{2}\left(\mathrm{D}_{0}\right)\right]$ is predicted at 3.50
$\mathrm{eV}(f=0.1151)$. This prediction matches very well with the strong band at $384 \mathrm{~nm}(3.23 \mathrm{eV}$, Ar matrix, $12 \mathrm{~K}$, spectrum not shown) and with the band at $388 \mathrm{~nm}(3.20 \mathrm{eV}$, Freon matrix, $77 \mathrm{~K}^{50}$ ).

Unlike the acenaphthylene radical cation, the geometry difference between neutral and cation does not significantly affect the excitation energies of acenaphthene radical cation at the B3LYP/6-31G(d,p) optimized neutral geometry, the BLYP/ $6-31 \mathrm{G}(\mathrm{d}, \mathrm{p})$ transition energies fall at $1.02\left({ }^{2} \mathrm{~B}_{2}\right), 2.06\left({ }^{2} \mathrm{~B}_{2}\right), 2.70$ $\left({ }^{2} \mathrm{~A}_{2}\right)$, and $2.88\left({ }^{2} \mathrm{~A}_{1}\right) \mathrm{eV}$. They agree with the observed photoelectron peak positions of $0.98,1.94,2.7$, and $2.9 \mathrm{eV}$ (all relative to the fundamental at $7.82 \mathrm{eV}) .{ }^{49}$ Again, we find excellent agreement between the calculated and observed onset position of the $\sigma$ ionization manifold at around $2.9 \mathrm{eV}$.

4. Photodehydrogenation of Neutral Acenaphthene. From our $\mathrm{C}-\mathrm{H}$ bond energy calculations and FT-ICR experiments (vide infra), the sequential loss of two hydrogens from the acenaphthene cation (neutral) to form the ACN cation (neutral) is expected. Our calculations reveal that the first hydrogen $\left(\mathrm{H}_{1^{\prime}}\right)$ lost from the acenaphthene cation (neutral) is one of the four identical hydrogens attached to the $\mathrm{sp}^{3}$ carbons on the fivemembered ring. The 2.67 (3.53) eV required to break this $\mathrm{C}-\mathrm{H}$ bond is approximately $50 \%(26 \%)$ lower than that required to break the $\mathrm{C}-\mathrm{H}$ bonds in the six-membered rings (cf., Figure 1). As expected, the second hydrogen $\left(\mathrm{H}_{2}\right)$ lost, on the remaining $\mathrm{sp}^{3}$ carbon, requires 3.21 (2.07) $\mathrm{eV}$ for removal. Thus the sequential loss of two hydrogens from the acenaphthene cation (neutral) likely results in the ACN cation (neutral).

Removal of the third hydrogen $\left(\mathrm{H}_{3}\right)$ from the six-membered ring requires a much higher energy, 4.77 (4.78) eV. However, because this calculated $\mathrm{C}-\mathrm{H}$ bond energy is only $6 \%(4 \%)$ lower than that of the other $\mathrm{C}-\mathrm{H}$ bonds in the six-membered rings, other dehydrogenation pathways may also be possible.

We present here direct spectroscopic evidence that confirms the theoretical expectation that acenaphthene can be converted into acenaphthylene upon photolysis. Figure 9a shows part of the IR absorption spectrum of acenaphthene before UV photolysis (upper panel) and after UV photolysis (lower panel). Photolysis causes the acenaphthene bands at 838.6 and 782.8 $\mathrm{cm}^{-1}$ to decrease in intensity by approximately $60 \%$, while the ACN bands at 832.4 and $773.7 \mathrm{~cm}^{-1}$ grow in.

Figure $9 \mathrm{~b}$ shows the UV/Visible electronic absorption spectra recorded on the same matrix under the same conditions as the IR spectra in Figure 9a. The $319 \mathrm{~nm}$ band $(0-0)$ of acenaphthene loses intensity during photolysis at a rate similar to the 838.6 and $782.8 \mathrm{~cm}^{-1}$ IR bands, while two new groups of bands 

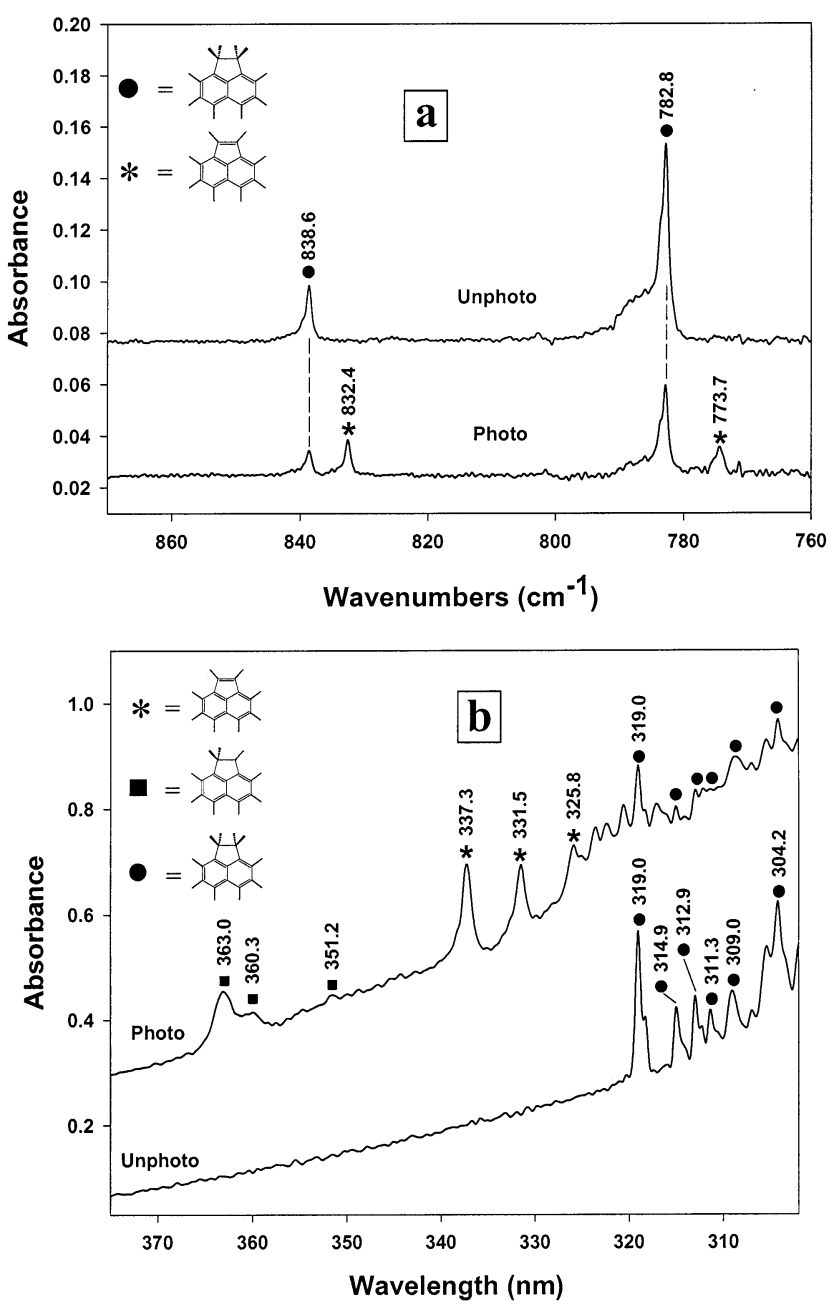

Figure 9. (a) Infrared absorption spectra of a matrix initially containing acenaphthene $\left(\mathrm{C}_{12} \mathrm{H}_{10}\right)$ isolated in solid $\mathrm{Ar}$ at $12 \mathrm{~K}$. Upper spectrum is before photolysis and lower spectrum is after photolysis $(2.5 \mathrm{~h}, 100 \mathrm{~W}$ medium-pressure $\mathrm{Hg}$ lamp, full spectral output). Upon photolysis, acenaphthene $\left(\mathrm{C}_{12} \mathrm{H}_{10}\right.$, black circles) converts (with $60 \%$ yield) to acenaphthylene $\left(\mathrm{C}_{12} \mathrm{H}_{8}\right.$, bands with stars). (b) UV/Visible absorption spectra of same matrix as in (a). Lower spectrum is before photolysis and upper is after photolysis (same conditions as in (a)). Upon photolysis, acenaphthene $\left(\mathrm{C}_{12} \mathrm{H}_{10}\right.$, black circles) dehydrogenates to singly dehydrogenated acenaphthene $\left(\mathrm{C}_{12} \mathrm{H}_{9}\right.$, bands with black squares) and to acenaphthylene $\left(\mathrm{C}_{12} \mathrm{H}_{8}\right.$, bands with stars $)$.

grow in (at 363.0, 360.3, and $351.2 \mathrm{~nm}$ and at 337.3, 331.5, and $325.8 \mathrm{~nm})$. The $337.3 \mathrm{~nm}$ group is assigned to the $\mathrm{S}_{2}\left({ }^{1} \mathrm{~A}_{1}\right)$ $\leftarrow \mathrm{S}_{0}\left({ }^{1} \mathrm{~A}_{1}\right)$ transition in neutral ACN. This is based both on the absorption spectrum recorded for this molecule and on TDDFT vertical excitation energy calculations (cf., Table 3). To assign the remaining new bands, vertical excitation energies were calculated for dehydrogenated acenaphthene, in which the $\mathrm{H}_{1}$ ' hydrogen is removed (cf., Figure 1). The results in Table 6 show that the strongest photofragment band at $363.0 \mathrm{~nm}$ (3.415 $\mathrm{eV})$ coincides very well with the strongest calculated transition at $3.36 \mathrm{eV}$. It is ascribed here to the $\mathrm{D}_{3}\left({ }^{2} \mathrm{~A}^{\prime \prime}\right) \leftarrow \mathrm{D}_{0}\left({ }^{2} \mathrm{~A}^{\prime \prime}\right)$ transition. The $360.3 \mathrm{~nm}(3.44 \mathrm{eV})$ and $351.2 \mathrm{~nm}(3.53 \mathrm{eV})$ experimental photofragment bands also agree well with calculated transitions for singly dehydrogenated acenaphthene (cf., Table 6). However, these bands are probably overlapped by vibronic bands of the strong $\mathrm{D}_{3} \leftarrow \mathrm{D}_{0}$ transition, and thus their assignment is tentative. The low yield of singly dehydrogenated neutral acenaphthene is most probably due to the much higher $\mathrm{C}-\mathrm{H}_{1^{\prime}}$ bond energy for this closed-shell system $\left(\mathrm{E}\left(\mathrm{C}-\mathrm{H}_{1^{\prime}}\right)=\right.$
TABLE 6: Vertical Excitation Energies (in eV) and Oscillator Strengths (in parentheses, "ia" represents inactive) of the Dehydrogenated Neutral Acenaphthene $\left(\mathrm{H}_{1^{\prime}}\right.$ off in Figure 1) Radical Calculated by Spin-Unrestricted TDDFT Employing the SVWN, BLYP, and B3LYP Functionals with the 6-31 $(2+, 2+) G(d, p) B_{\text {Basis Set }}{ }^{a}$

\begin{tabular}{lcccc}
\hline \multicolumn{1}{c}{ state $^{b}$} & SVWN & BLYP & B3LYP & $\begin{array}{c}\text { experi- } \\
\text { ment }\end{array}$ \\
\hline${ }^{2} \mathrm{~A}^{\prime \prime}\left(\pi_{0} \leftarrow \pi_{-1}\right)$ & $2.20(0.0002)$ & $2.22(0.0005)$ & $2.48(0.0011)$ & \\
${ }^{2} \mathrm{~A}^{\prime \prime}\left(\pi_{0} \leftarrow \pi_{-2}\right)$ & $2.57(0.0066)$ & $2.63(0.0059)$ & $2.98(0.0044)$ & \\
${ }^{2} \mathrm{~A}^{\prime \prime}\left(\pi_{1} \leftarrow \pi_{0}\right)$ & $2.88(0.0505)$ & $2.93(0.0547)$ & $3.36(0.0942)$ & $3.415^{c}$ \\
${ }^{2} \mathrm{~A}^{\prime \prime}\left(\pi_{2} \leftarrow \pi_{0}\right)$ & $3.05(0.0405)$ & $3.12(0.0380)$ & $3.53(0.0391)$ & $3.44^{c}$ \\
${ }^{2} \mathrm{~A}^{\prime}\left(\sigma_{1} \leftarrow \pi_{0}\right)$ & $3.59(0.0004)$ & $3.32(0.0004)$ & $3.80(0.0005)$ & \\
${ }^{2} \mathrm{~A}^{\prime}\left(\sigma_{2} \leftarrow \pi_{0}\right)$ & $3.88(0.0000)$ & $3.57(0.0000)$ & $4.08(0.0000)$ & \\
${ }^{2} \mathrm{~A}^{\prime \prime}\left(\pi_{0} \leftarrow \pi_{-3}\right)$ & $3.58(0.0077)$ & $3.59(0.0056)$ & $4.05(0.0057)$ & $3.53^{c}$ \\
${ }^{2} \mathrm{~A}^{\prime}\left(\sigma_{3} \leftarrow \pi_{0}\right)$ & $3.92(0.0000)$ & $3.60(0.0000)$ & $4.14(0.0000)$ & \\
${ }^{2} \mathrm{~A}^{\prime \prime}\left(\pi_{3} \leftarrow \pi_{0}\right)$ & $4.23(0.0263)$ & $3.88(0.0020)$ & $4.36(0.0026)$ & \\
${ }^{2} \mathrm{~A}^{\prime}\left(\sigma_{4} \leftarrow \pi_{0}\right)$ & $4.28(0.0000)$ & $3.95(0.0000)$ & $4.48(0.0001)$ &
\end{tabular}

${ }^{a}$ The geometry is optimized at the B3LYP/6-31G(d,p) level. The carbon skeleton lies in the $x y$ plane with the longer molecular axis parallel to the $x$ axis. The ground-state wave function transforms as $\mathrm{A}_{2}$ irreducible representation in $C_{s}$ symmetry. ${ }^{b}$ The $\pi$ and $\sigma$ orbitals are numbered in the order of increasing orbital energies. The $\pi_{-1}, \pi_{0}$, and $\pi_{1}$ denote the highest doubly occupied, the singly occupied, and the lowest unoccupied $\pi$ orbitals, respectively. ${ }^{c}$ In solid Ar, this work.

$3.53 \mathrm{eV})$ compared to the cationic open-shell form $\left(E\left(\mathrm{C}-\mathrm{H}_{1^{\prime}}\right)\right.$ $=2.67 \mathrm{eV})$.

C. FT-ICR Photodissociation of the Acenaphthene Cation. Because the acenaphthene cation was identified as a hydrogenation product of the ACN cation, Fourier transform ion cyclotron resonance photodissociation experiments were conducted to establish photodegradation pathways for the parent acenaphthene cation and its fragments.

1. Acenaphthene Cation $\left(\mathrm{C}_{12} \mathrm{H}_{10}{ }^{+}\right)$. When Ekern et al. ${ }^{28}$ observed that UV irradiation of the acenaphthene cation $(\mathrm{m} / \mathrm{z}$ 154) yielded only dehydrogenated photoproducts, only single and double hydrogen loss from the parent ion was seen. In the current work, loss of up to four hydrogens has been observed. Although the mechanism of hydrogen loss was not previously investigated, it has been proposed in general that the dehydrogenation of PAH cations may occur sequentially or as double hydrogen loss. To distinguish between the different fragmentation pathways, SWIFT ejection waveforms were applied during lamp irradiation. Because ions removed during photolysis cannot be fragmented to form any of the lower $\mathrm{m} / \mathrm{z}$ photoproducts, this approach may be used to determine the direct photoproducts of the retained (isolated) ion. Complete ejection of ions could not be achieved without severely degrading the resolution of the detected mass spectrum, so fragment ion ratios and percent reductions were monitored to determine dehydrogenation pathways.

2. Photolysis of the $\mathrm{m} / \mathrm{z}, 154$ Fragment Ion. After formation of the $\mathrm{C}_{12} \mathrm{H}_{10}{ }^{+}$ion by electron bombardment (Figure 10a), the $m / z, 154$ species was isolated. Photolysis of the $\mathrm{C}_{12} \mathrm{H}_{10}{ }^{+}(\mathrm{m} / \mathrm{z}$ 154) parent ion for $1.5 \mathrm{~s}$ yielded photofragments of $\mathrm{m} / \mathrm{z}, 153$, 152, 151, and 150 (cf., Figure 10b). Ejection of the $\mathrm{m} / \mathrm{z} 153$ ion during irradiation of the $\mathrm{m} / \mathrm{z}, 154$ parent ion resulted in a decrease in the abundance of the $\mathrm{m} / \mathrm{z}, 152,151$, and 150 photofragments (cf., Figure 10c). The $m / z, 153$ fragment abundance undergoes a $96 \%$ reduction (due to the ejection waveform) while the $\mathrm{m} / \mathrm{z} 152,151$, and 150 abundances undergo $93 \%, 91 \%$, and $90 \%$ reductions, respectively. We conclude that the major pathway of $\mathrm{m} / \mathrm{z}, 152$ formation is single hydrogen loss from the $m / z 153$ ion rather than double hydrogen loss from the $m / z, 154$ parent ion. 

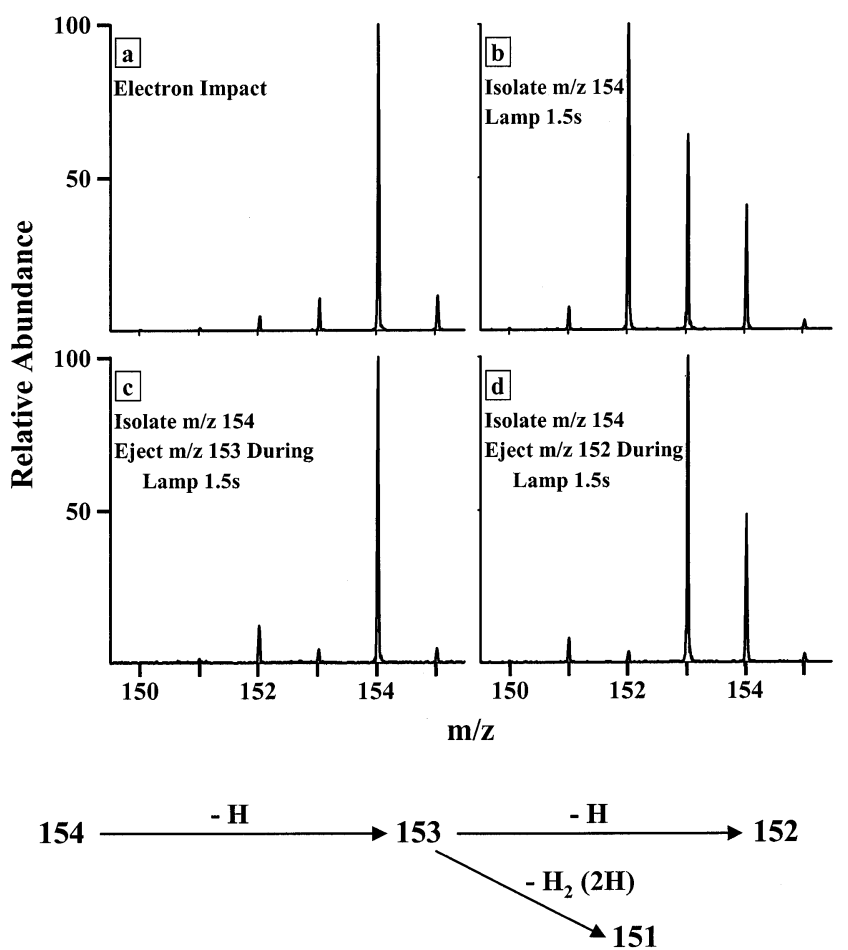

Figure 10. (a) FT-ICR mass spectra of acenaphthene cation $(\mathrm{m} / \mathrm{z}, 154)$ recorded after electron impact, (b) photofragmentation for $1.5 \mathrm{~s}$ using Xe lamp with no ejection, (c) same as (b) but with ejection of $\mathrm{m} / \mathrm{z} 153$ ion fragment, and (d) same as (b) but with ejection of $\mathrm{m} / \mathrm{z} 152$ ion fragment. Proposed photofragmentation pathways for acenaphthene cation are sketched at the bottom.

Ejection of the $m / z, 152$ ion during lamp photolysis resulted in a $97 \%$ loss of the $\mathrm{m} / \mathrm{z}, 152$ ion, but only a $7 \%$ and $10 \%$ loss of the $m / z 151$ and 150 ions, respectively (Figure 10d). Thus, it appears that the $\mathrm{m} / \mathrm{z}, 151$ and 150 photofragments form independently of the $\mathrm{m} / \mathrm{z} 152$ ion. Consequently, the only remaining pathway available for the formation of $\mathrm{m} / \mathrm{z} 151$ requires double hydrogen loss from the $m / z 153$ ion. Furthermore, the lack of correlation of the $\mathrm{m} / \mathrm{z} 151$ and 150 ions with the $\mathrm{m} / \mathrm{z}, 152$ ion indicates that the $\mathrm{m} / \mathrm{z}, 152$ ion is photostable.

Ejection of the $m / z, 151$ ion during lamp photolysis resulted in the complete disappearance of the $\mathrm{m} / \mathrm{z} 150$ ion. Thus, even though percent reductions are incalculable due to the absence of $\mathrm{m} / \mathrm{z}, 150$ and 151 peaks in the final mass spectrum, the $\mathrm{m} / \mathrm{z}$ 150 ion is apparently produced by single hydrogen loss from the $m / z 151$ precursor.

3. Photolysis of the $\mathrm{m} / \mathrm{z}, 153$ Fragment Ion. Irradiation of the $\mathrm{C}_{12} \mathrm{H}_{9}{ }^{+}(\mathrm{m} / \mathrm{z}$ 153) fragment ion for $1.5 \mathrm{~s}$ produced $\mathrm{m} / \mathrm{z}, 152,151$, and 150 fragment ions. As observed during photolysis of the $\mathrm{m} / \mathrm{z} 154$ parent ion, ejection of the $\mathrm{m} / \mathrm{z} 152$ ion during lamp irradiation did not eliminate the $\mathrm{m} / \mathrm{z} 151$ and 150 ions. As a result, these two lower-mass ions do not appear to be formed by dehydrogenation of the $\mathrm{m} / \mathrm{z}, 152$ ion. Again, ejection of the $\mathrm{m} / \mathrm{z}, 151$ ion during photolysis resulted in the complete disappearance of the $\mathrm{m} / \mathrm{z} 150$ ion, indicating single hydrogen loss from the $\mathrm{m} / \mathrm{z}, 151$ species to form the $\mathrm{m} / \mathrm{z}, 150$ photoproduct.

4. Photolysis of the $\mathrm{m} / \mathrm{z} 152$ Fragment Ion. Total isolation of the $\mathrm{C}_{12} \mathrm{H}_{8}{ }^{+}(\mathrm{m} / \mathrm{z}, 152)$ ion could not be achieved. The results of photolysis of the $\mathrm{m} / \mathrm{z} 152$ ion thus remain inconclusive. Irradiation of the partially isolated $\mathrm{m} / \mathrm{z}, 152$ ion produced both $\mathrm{m} / \mathrm{z} 151$ and 150 photoproducts; however, since the $\mathrm{m} / \mathrm{z} 154$ and 153 ions could not be completely removed prior to photolysis, it is unclear whether the $\mathrm{m} / \mathrm{z} 151$ and 150 ions are produced by photolysis of the $m / z, 152$ or the $m / z, 153$ ion. The photodissociation yield of the isolated ACN cation $(\mathrm{m} / \mathrm{z}, 152)$ was too low to track its photodissociation pathways.

\section{Relation of Absorption and Photodissociation IR Spectra to the UIR Emission Spectra}

The infrared spectra of neutral and ionic ACN exhibit many band characteristics similar to other PAH species studied to date. In the neutral species, the most intense modes are the out-ofplane $\mathrm{C}-\mathrm{H}$ bends and the in-plane $\mathrm{C}-\mathrm{C}$ stretches, while in the cationic species, the most intense bands are the in-plane $\mathrm{C}-\mathrm{H}$ bending motions and $\mathrm{C}-\mathrm{C}$ stretching modes. There is, however, one major difference. The most intense IR modes for sixmembered ring $\mathrm{PAH}$ cations fall within the spectral range of $1200-1550 \mathrm{~cm}^{-1}(6.5-8.3 \mu \mathrm{m})$ for absorption and within $1160-1530 \mathrm{~cm}^{-1}(6.5-8.6 \mu \mathrm{m})$ for the photodissociation spectrum. However, the intense bands in the absorption and photodissociation spectra of the ACN cation appear at ca. 1183$1063 \mathrm{~cm}^{-1}(8.5-9.4 \mu \mathrm{m})$. While the UIR bands have emission output in this range, no peaks are present from any sources at $9.4 \mu \mathrm{m}$. Thus, we conclude that the ACN cation is probably not a major contributor to the UIR bands. It will be of interest to determine whether other, much larger PAHs containing one or more five-membered rings display the correct spectral features to merit consideration as UIR contributors.

\section{Conclusions}

(1) The infrared spectrum of neutral acenaphthylene has been measured in an Ar matrix at $12 \mathrm{~K}$ and its bands assigned with the aid of density functional theory calculations (B3LYP/6$31 \mathrm{G}(\mathrm{d})$ and BP86/6-31G(d)). Good agreement was found.

(2) Infrared spectra of acenaphthylene cations, formed by electron bombardment of an ACN/Ar effusive beam, then deposited in an Ar matrix at $12 \mathrm{~K}$, were measured and the observed bands were compared to B3LYP/6-31G(d) and BP86/ 6-31G(d) frequency calculations. Reasonable agreement was found, though not as satisfactory as for the neutral species.

(3) Infrared photodissociation spectra of the ACN cation, using a high-intensity tunable infrared source (free electron laser), were also measured and compared to both matrix spectra and calculated frequencies. Good agreement with the matrix spectrum was found.

(4) Infrared spectral evidence shows that, after electron bombardment of an effusive acenaphthylene /Ar beam, hydrogenation of $\mathrm{ACN}$, via hydrogen atom migration in the matrix, forms singly and doubly hydrogenated ACN (i.e., acenaphthene).

(5) Electronic excitation energies and oscillator strengths for neutral and cationic acenaphthylene, cationic acenaphthene, and singly dehydrogenated neutral acenaphthene have been calculated using time-dependent density functional theory (TDDFT) with several functionals (SVWN, BLYP, and B3LYP) with the 6-31 G(d,p) basis set. Electronic absorption matrix spectra of acenaphthylene in Ar and acenaphthene in Ar, with and without gas-phase electron bombardment, and with and without matrixphase photolysis, were also recorded. These results confirm the infrared results that electron-bombarded acenaphthylene converts to its doubly hydrogenated form, acenaphthene, in the matrix. Upon photolysis, matrix-isolated acenaphthene dehydrogenates to form singly dehydrogenated and doubly dehydrogenated species (i.e., acenaphthylene).

(6) Fourier transform ICR measurements of the acenaphthene cation revealed that dehydrogenation takes place sequentially from the acenaphthene parent ion $(\mathrm{m} / \mathrm{z}, 154)$ to acenaphthylene $(\mathrm{m} / \mathrm{z}, 152)$, but that double-dehydrogenation may occur from the $\mathrm{m} / z, 153$ fragment to the $\mathrm{m} / z, 151$ ion. DFT calculations of the 
acenaphthene cation $\mathrm{CH}$ bond energies show that the hydrogens lost in the dehydrogenation process are those attached to the $\mathrm{sp}^{3}$ carbons of the five-membered ring.

(7) The potential contribution of the ACN cation to the interstellar UIR bands is doubtful. It exhibits a strong IR band at $9.4 \mathrm{~mm}$, which the UIR bands do not.

Acknowledgment. The authors gratefully acknowledge the donors of the Petroleum Research Fund, administered by the American Chemical Society, for their support of this research. S.H. was supported by the U.S. Department of Energy, Office of Basic Energy Sciences at the Pacific Northwest National Laboratory operated by Battelle Memorial Institute. M.H.G. gratefully acknowledges the support from the Director, Office of Energy Research, Office of Basic Energy Sciences, Chemical Science Division of the U.S. Department of Energy under Contract No. DE-ACO 3-76SF00098. This work is part of the research program of FOM, which is financially supported by the Nederlandse Organisatie voor Wetenschappelijk Onderzoek (NWO).

\section{References and Notes} 83,87

(1) Gillett, F. C.; Forrest, W. G.; Merrill, K. M. Astrophys. J. 1973,

(2) Duley W. W.; Williams, D. A.; Mon. N. R. Astron. Soc. 1981, 196, 269.

(3) Leger, A.; Puget, J. L. Astron. Astrophys. 1984, 137, L5.

(4) Allamandola, L. J.; Tielens, A. G. G. M.; Barker, J. Astrophys. J.

1985, 290, L25; ibid 1989, 71, 733.

(5) Frenklach, M.; Feigelson, E. D. Astrophys. J. 1989, 341, 372

(6) Keller, R. In Polycyclic Aromatic Hydrocarbons; Leger, A. d'Hendecourt, L., Boccara, N., Eds.; Reidel: Dordrecht, 1987; p 3.

(7) Gail, H. P.; Sedlmayr, E. In Physical Processes in Interstellar Clouds; Morfill, G. E., Scholer, M., Eds.; Reidel: Dordrecht, 1987; p 275.

(8) Szczepanski, J.; Vala, M. Astrophys. J. 1993, 414, 646.

(9) Szczepanski, J.; Vala, M. Nature 1993, 363, 699.

(10) Hudgins, D. M.; Sandford, S. A.; Allamandola, L. J. J. Phys. Chem. 1994, 98,4243

(11) Hudgins, D. M.; Allamandola, L. J. J. Phys. Chem. 1995, 99, 3033

(12) Geballe, T. R.; Tielens, A. G. G. M.; Allamandola, L. J.; Moorhouse, A.; Brand, P. W. J. L. Astrophys. J. 1989, 341, 278.

(13) Geballe, T. R.; Lacy, J. H.; Persson, S. E.; McGregor, P. J.; Soifer,

B. T. Astrophys. J. 1985, 292, 500 .

(14) Nagata, T.; Tokunaga, A.; Sellgren, K.; Smith, R. G.; Onaka, T.; Nakada, Y.; Sakata, A. Astrophys. J. 1988, 326, 157.

(15) Joblin, C.; Tielens, A. G. G. M.; Geballe, T. R.; Wooden, D. H. Astrophys. J. 1996, 460, L119-L122.

(16) Schlemmer, S.; Cook, D. J.; Harrison, J. A.; Wurfel, B.; Chapman,

W.; Saykally, R. J. Science 1994, 265, 1686.

(17) Cook, D. J.; Schlemmer, S.; Balucani, N.; Wagner, D. R.; Steiner,

B.; Saykally, R. J. Nature 1996, 380, 227.

(18) Kim, H. S.; Wagner, D. R.; Saykally, R. J. Phys. Rev. Lett. 2001 $86,5691$.

(19) Pauzat, F.; Talbi, D.; Ellinger, Y. Astron. Astrophys. 1997, 319 318 , and references therein.

(20) Boissel, P.; Lefevre, G.; Thiebot, P. Molecules and Grains in Space; Nenner, I., Ed.; American Institute of Physics Press: New York, 1993; p 667.

(21) Boissel, P.; de Parseval, P.; Marty, P.; Lefevre, G. J. Chem. Phys. 1997, 106, 4973.

(22) Piest, J. A.; von Helden, G.; Meijer, G. Astrophys. J. Lett. 1999, 520 , L75.

(23) Satink, R. G.; Piest, J. A.; von Helden, G.; Meijer, G. J. Chem. Phys. 1999, 111, 10750. 404.

24) Oomens, J.; van Roij, A. J. A.; Meijer, G. Astrophys. J. 2000, 542,

(25) Piest, J. A.; Oomens, J.; Bakker, J. M.; von Helden, G.; Meijer, G. Spectrosc. Chim. Acta A 2001, 57, 717.

(26) Oomens, J.; Meijer, G.; von Helden, G. J. Phys. Chem. A 2001, 105,8302 .

(27) Ekern, S.; Marshall, A. G.; Szczepanski, J.; Vala, M. Astrophys. J. 1997, 488, L39.

(28) Ekern, S.; Marshall, A. G.; Szczepanski, J.; Vala, M. J. Phys. Chem. 1998, 102, 3498.

(29) Ling, Y.; Martin, J. M. L.; Lifshitz, C. J. Phys. Chem. 1997, 101, 219 .

(30) Szczepanski, J.; Vala, M.; Talbi, D.; Parisel, O.; Ellinger, Y. J. Chem. Phys. 1993, 98, 4494

(31) Szczepanski, J.; Banisaukas, J.; Vala, M.; Hirata, S.; Bartlett, R. J.; Head-Gordon, M. J. Phys. Chem. A 2002, 106, 63.

(32) Bauschlicher, C. W., Jr.; Hudgins, D. M.; Allamandola, L. J. Theor. Chem. Acc. 1999, 103, 154.

(33) (a)Yang, Y.; Linnert, H. V.; Riveros, J. M.; Williams, K. R.; Eyler, J. R. J. Phys. Chem. 1997, 101, 2371. (b) Dibben, M. J.; Kage, D.; Szczepanski, J.; Eyler, J.; Vala, M. J. Phys. Chem. 2001, 105, 6024.

(34) Senko, M. W.; Canterbury, J. D.; Guan, S.; Marshall, A. G. Rapid Commun. Mass Spectrom. 1996, 10, 1839.

(35) Frisch, M. J.; Trucks, G. W.; Schlegel, H. B.; Scuseria, G. E.; Robb, M. A.; Cheeseman, J. R.; Zakrzewski, V. G.; Montgomery, J. A., Jr.; Stratmann, R. E.; Burant, J. C.; Dapprich, S.; Millam, J. M.; Daniels, A. D.; Kudin, K. N.; Strain, M. C.; Farkas, O.; Tomasi, J.; Barone, V.; Cossi, M.; Cammi, R.; Mennucci, B.; Pomelli, C.; Adamo, C.; Clifford, S.; Ochterski, J.; Petersson, G. A.; Ayala, P. Y.; Cui, Q.; Morokuma, K.; Malick, D. K.; Rabuck, A. D.; Raghavachari, K.; Foresman, J. B.; Cioslowski, J.; Ortiz, J. V.; Stefanov, B. B.; Liu, G.; Liashenko, A.; Piskorz, P.; Komaromi, I.; Gomperts, R.; Martin, R. L.; Fox, D. J.; Keith, T.; Al-Laham, M. A.; Peng, C. Y.; Nanayakkara, A.; Gonzalez, C.; Challacombe, M.; Gill, P. M. W.; Johnson, B. G.; Chen, W.; Wong, M. W.; Andres, J. L.; Head-Gordon, M.; Replogle, E. S.; Pople, J. A. Gaussian 98, revision A.3; Gaussian, Inc.: Pittsburgh, PA, 1998.

(36) Becke, A. D. J. Chem. Phys. 1993, 98, 5648.

(37) Lee, C.; Yang, W.; Parr, R. Phys. Rev. B 1988, 37, 785.

(38) Langhoff, S. R. J. Phys. Chem. 1996, 100, 2819.

(39) Slater J. C. Quantum Theory of Molecules and Solids, Vol. 4: The Self-Consistent Field for Molecules and Solids; McGraw-Hill: New York, 1974

(40) Vosko, S. H.; Wilk, L.; Nusair, M. Can. J. Phys. 1980, 58, 1200

(41) Becke, A. D. Phys. Rev. A 1988, 38, 3098

(42) Kong, J.; White, C. A.; Krylov, A. I.; et al. J. Comput. Chem 2000, 21, 1532

(43) Hirata, S.; Lee, T. J.; Head-Gordon, M. J. Chem. Phys. 1999, 111, 8904.

(44) Casida, M. E.; Jamorski, C.; Casida, K. C.; Salahub, D. R. J. Chem. Phys. 1998, 108, 4439 .

(45) Radziszewski, J. G.; Abildgaard, J.; Thulstrup, E. W. Spectrochim. Acta A 1997, 53, 2095.

(46) Rogers, E. E.; Abramowitz, S.; Jacox, M. E.; Milligan, D. E. J. Chem. Phys. 1970, 52, 2198

(47) Oomens, J.; Sartakov, B. G.; Tielens, A. G. G. M.; Meijer, G. von Helden, G. Astrophys. J. Lett. 2001, 560, L99-L103.

(48) Nakimovsky, L. A.; Lamotte, M.; Joussot-Dubien, J. Handbook of Low-Temperature Electronic Spectra of Polycyclic Aromatic Hydrocarbons; Elsevier: New York, 1989

(49) Boschi, R.; Clar, E.; Schmidt, W. J. Chem. Phys. 1974, 60, 4406.

(50) Shida, T. Electronic Absorption Spectra of Radical Ions; Elsevier: Amsterdam, 1988.

(51) Bauschlicher, C. W., Jr. Astrophys. J. 1998, 509, L125-L127.

(52) Szczepanski, J.; Dibben, M. J.; Pearson, W.; Eyler J. R.; Vala, M. J. Phys. Chem. 2001, 105, 9388

(53) Szczepanski, J.; Banisaukas, J.; Vala, M.; Hirata, S. J. Phys. Chem. A 2002, 106, 6935 . 